\title{
The Role of Gasotransmitters in Gut Peptide Actions
}

\author{
Wout Verbeure ${ }^{1}$, Harry van Goor ${ }^{2}$, Hideki Mori ${ }^{1}$, André P. van Beek ${ }^{2}$, Jan Tack ${ }^{1 *}$ and \\ Peter R. van Dijk ${ }^{2}$ \\ ${ }^{1}$ Translational Research Center for Gastrointestinal Disorders, KU Leuven, Leuven, Belgium, ${ }^{2}$ Departement of Endocrinology, \\ University Medical Center Groningen, Groningen, Netherlands
}

\section{OPEN ACCESS}

Edited by:

Ralf Weiskirchen,

RWTH Aachen University, Germany

Reviewed by:

Wei Liu,

University of Science and Technology of China, China

Medardo Hernández, Complutense University of Madrid,

Spain

Jerzy Beltowski,

Medical University of Lublin, Poland

${ }^{*}$ Correspondence:

Jan Tack

jan.tack@med.kuleuven.be

Specialty section:

This article was submitted to Gastrointestinal and Hepatic Pharmacology,

a section of the journal Frontiers in Pharmacology

Received: 04 June 2021 Accepted: 07 July 2021

Published: 20 July 2021

Citation:

Verbeure W, van Goor $\mathrm{H}$, Mori $\mathrm{H}$, van Beek AP, Tack J and van Dijk PR (2021) The Role of Gasotransmitters in

Gut Peptide Actions.

Front. Pharmacol. 12:720703.

doi: 10.3389/fphar.2021.720703
Although gasotransmitters nitric oxide (NO), carbon monoxide $(\mathrm{CO})$ and hydrogen sulfide $\left(\mathrm{H}_{2} \mathrm{~S}\right)$ receive a bad connotation; in low concentrations these play a major governing role in local and systemic blood flow, stomach acid release, smooth muscles relaxations, antiinflammatory behavior, protective effect and more. Many of these physiological processes are upstream regulated by gut peptides, for instance gastrin, cholecystokinin, secretin, motilin, ghrelin, glucagon-like peptide 1 and 2 . The relationship between gasotransmitters and gut hormones is poorly understood. In this review, we discuss the role of NO, CO and $\mathrm{H}_{2} \mathrm{~S}$ on gut peptide release and functioning, and whether manipulation by gasotransmitter substrates or specific blockers leads to physiological alterations.

Keywords: gut peptide, nitric oxide, carbon monoxide, hydrogen sulfide, gasotransmitters

\section{INTRODUCTION}

A variety of gastrointestinal hormones provide the regulation of digestive processes. Aberrant gut peptide release or function has been implicated in disorders of the gastrointestinal tract and may lead to several symptoms as shown in dumping syndrome, irritable bowel syndrome, functional dyspepsia and gastroparesis (Camilleri, 2014; Van den Houte et al., 2020). Enteroendocrine cells in the stomach, small intestine and pancreas receive neuronal and nutritional information and accordingly secrete or contain their content. Emerging evidence shows a potential role of gasotransmitters in the regulation and function of gut hormones. Small gaseous signaling molecules, such as nitric oxide (NO), carbon monoxide ( $\mathrm{CO})$ and hydrogen sulfide $\left(\mathrm{H}_{2} \mathrm{~S}\right)$, can freely pass the cell membrane and manage functions in these enteroendocrine cells (Wang, 2002).

NO, the first discovered gasotransmitter, has been extensively studied. It is a key regulator in processes such as blood vessel dilatation (Vallance et al., 1989). It is also involved in muscle relaxation such as the relaxation of the fundic area after a meal, called the gastric accommodation (Tack et al., 2002). Arginine amino acid is the substrate from which NO is generated by the enzyme nitric oxide synthase (NOS) (Figure 1). Three different NOS isoforms exist: neuronal NOS (nNOS), endothelial NOS (eNOS) and inducible (inflammatory) NOS (iNOS). The first two produce the required concentrations in healthy situations to regulate physiological functions as earlier mentioned. The latter is mainly present in macrophages and is able to produce high amounts of NO to cope with a stress factor as e.g., an infection (Förstermann and Kleinert, 1995). Exogenous NO precursors can be found as food supplements (Bescós et al., 2012), or synthetic forms with longer activity like isosorbide mononitrate (Abshagen, 1992). The nitroaspirin (NCX-4016) is a NO releasing derivative of aspirin that inhibits platelet aggregation induced by adenosine diphosphate and thrombin agonists as an action of aspirin, and protects the stomach from aspirin-induced gastric mucosal damage by NO (Burgaud et al., 2002; Fiorucci et al., 2003). Inhalation of low NO concentrations (INOmax) leads to bronchodilation (Bin-Nun and Schreiber, 2008). Sildenafil does not contain a substrate, but it 


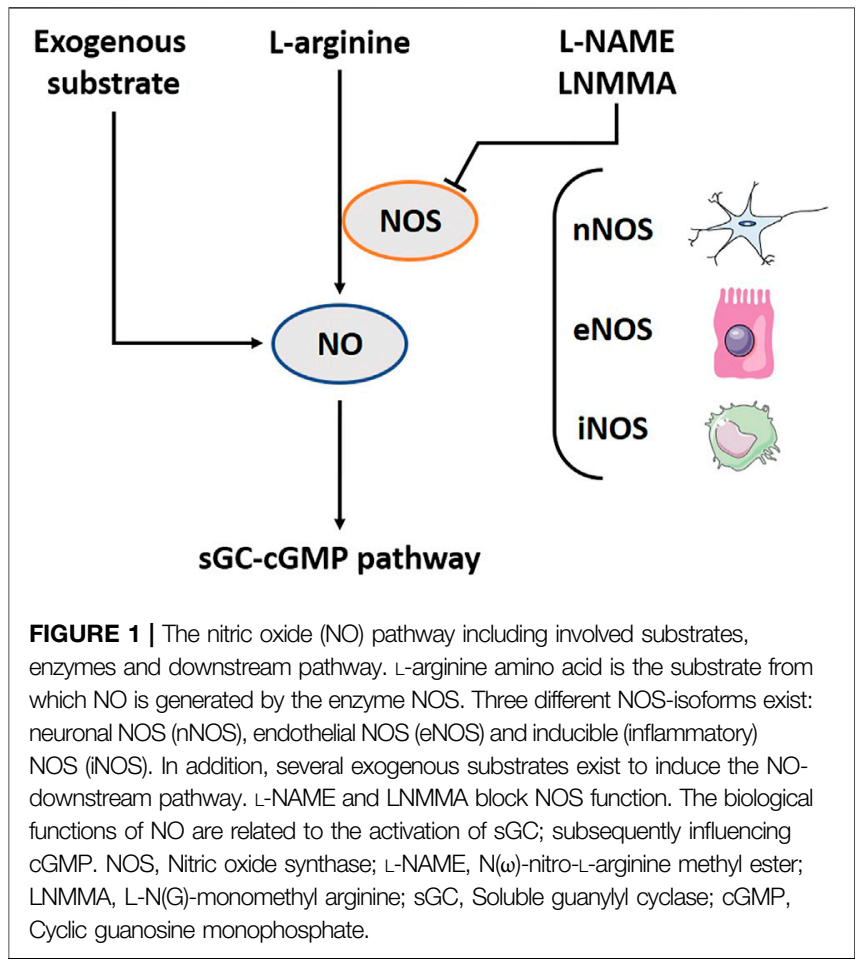

interacts with the downstream NO-pathway as a phosphodiesterase five inhibitor (Corinaldesi et al., 2016). L-arginine analogues, like $\mathrm{N}(\omega)$-nitro-L-arginine methyl ester (L-NAME) and L-N(G)-monomethyl arginine (LNMMA), are chemical compounds, which block NOS function, a required tool for further research (Robbins and Grisham, 1997; Kopincová et al., 2012). Furthermore, NO is extremely reactive and has a half-life time of mere seconds (Hakim et al., 1996). It is supposed to be mostly active at the site of production and the surrounding cells.

CO has colloquially received a bad connotation. However, scientists now start to understand its physiological relevance (Kim et al., 2006). Haem is catabolized by two oxygenase proteins: haem oxygenase 1 (HO-1) which is additionally activated during inflammation or a period of oxidative stress, and haem oxygenase 2 (HO-2) which is constitutively active (Maines, 1997; Motterlini et al., 1998) (Figure 2). HO-1 can be found in human gastric epithelial cells and in inflammatory cells in the lamina propria. It has been suggested that nutritional modulations may be used as an intervention for local inflammation (Coëffier et al., 2002). HO-2 is more broadly expressed than HO-1 and can be found in the brain, liver and vascular endothelial cells (Maines, 1988; Ewing and Maines, 1992). In the gut, it is present in the myenteric and submucosal plexus in the jejunum (Matsuda et al., 2010). In Hirschsprung's disease, the impaired inhibitory motor control is a prominent symptom, and associates with downregulation in $\mathrm{HO}-$ 2 mRNA (Chen et al., 2002). Under aerobe conditions, luminal bacteria also produce CO (Engel et al., 1972), though this is considered a small proportion of the total production (Hermann et al., 2012). This gasotransmitter differentiates itself from NO

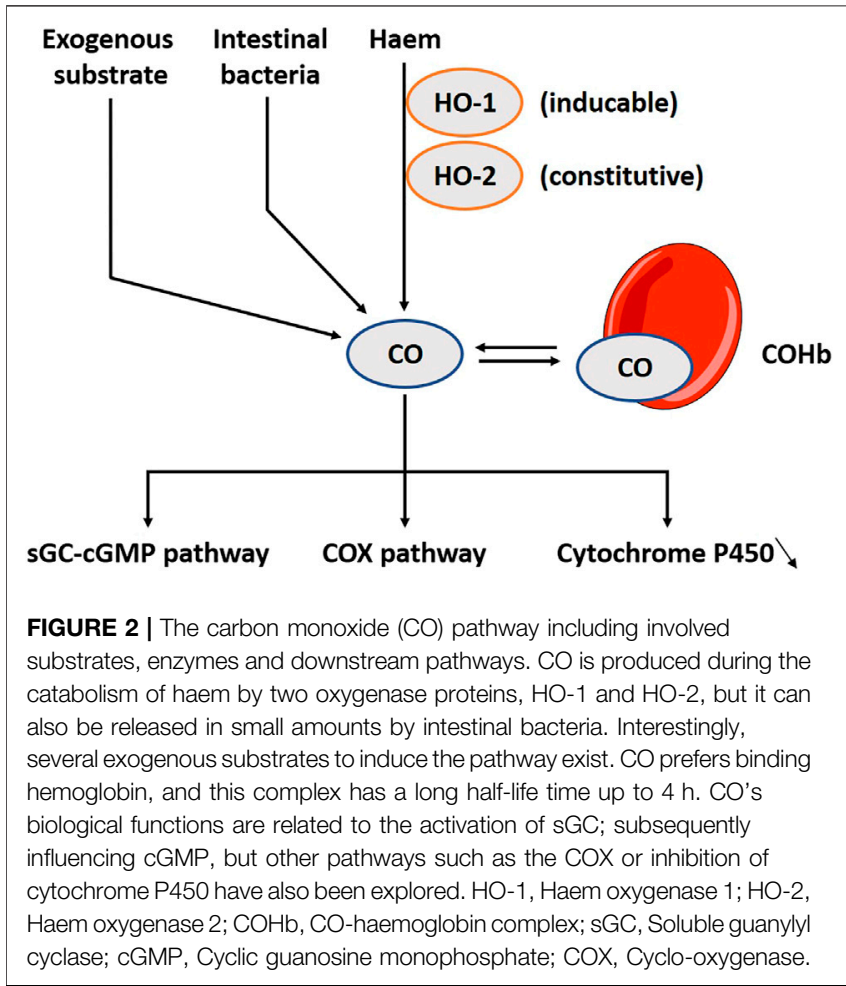

and $\mathrm{H}_{2} \mathrm{~S}$ as a more stable molecule. It prefers binding hemoglobin, and this complex has a long half-life time up to $4 \mathrm{~h}$ (Pan et al., 2020). Its biological functions are related to the activation of soluble guanylyl cyclase (sGC); subsequently influencing cGMP, but other pathways such as the cyclooxygenase $(\mathrm{COX})$ or inhibition of cytochrome $\mathrm{P} 450$ are also reported (Mancuso et al., 1997). CO is not as effective for activating sGC as NO (Stone and Marletta, 1994), but when intracellular levels of $\mathrm{NO}$ are low, CO functions as a back-up system (Wu and Wang, 2005; Moustafa and Habara, 2014a). Exogenous inhalation of $\mathrm{CO}$ gas induces a wide range of beneficial responses (Foresti et al., 2008). CO releasing molecules (CORMs) are metal carbonyl complexes releasing $\mathrm{CO}$ dose-controlled and tissue-specific. These potential clinical applications are dominantly tested in cell-lines and animal models with little to none studies done in humans (Naito et al., 2016; Steiger et al., 2016). A broad range of CORMs functions are already discussed in depth elsewhere (Foresti et al., 2008; Ismailova et al., 2018; Ling et al., 2018).

$\mathrm{H}_{2} \mathrm{~S}$ has only recently joined the group of gasotransmitters. Therefore, its relevance has been less well studied. There are two enzymatic pathways in the production of $\mathrm{H}_{2} \mathrm{~S}$, cystathionine gammalyase (CSE) and cystathionine beta-synthase (CBS), the so-called transsulfuration pathways (Wang, 2002) (Figure 3). A third enzymatic pathway primarily exists in mitochondria, the cysteine catabolic pathways by 3-mercatopyruvate sulfurtransferase (3-MST) (Shibuya et al., 2009). The pyridoxal phosphate cofactor form of vitamin $\mathrm{B} 6$, in the presence of $\mathrm{Fe}^{3+}$, is essential to catalyze the enzymatic $\mathrm{H}_{2} \mathrm{~S}$ production via CSE and CBS. In addition, vitamin B6 and iron are also required for the non-enzymatic synthesis of $\mathrm{H}_{2} \mathrm{~S}$ 


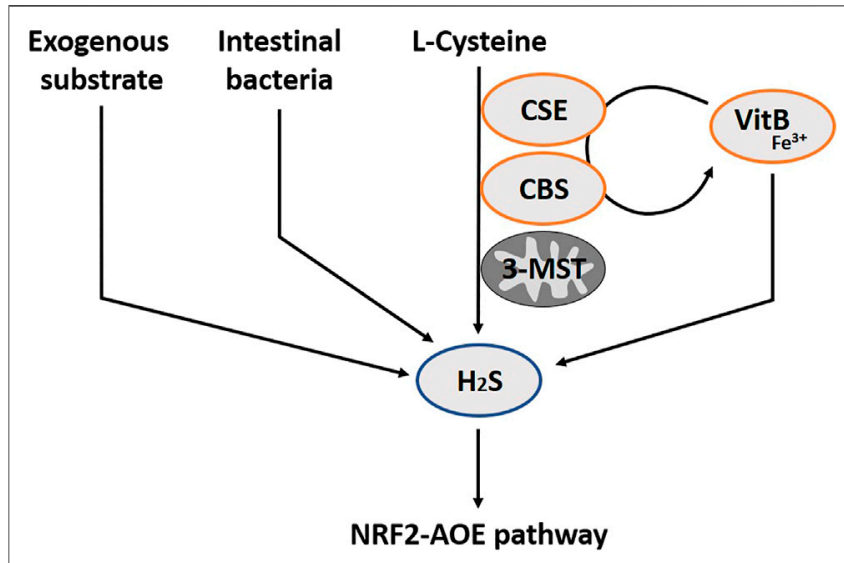

FIGURE 3 | The hydrogen sulfide pathway $\left(\mathrm{H}_{2} \mathrm{~S}\right)$ including involved substrates and enzymes. $\mathrm{H}_{2} \mathrm{~S}$ is produced through enzymatic pathways of CSE, CBS and 3-MST. In addition, intestinal bacteria can also secrete $\mathrm{H}_{2} \mathrm{~S}$, and several exogenous substrates exist. Vitamin B6 and iron are also required for the non-enzymatic synthesis of $\mathrm{H}_{2} \mathrm{~S}$ in blood. $\mathrm{H}_{2} \mathrm{~S}$ exerts antioxidant effects through several mechanisms, such as increasing expression of AOE, by activating the transcription factor NRF2. CSE, Cystathionine gamma-lyase; CBS, Cystathionine beta-synthase; 3-MST, 3mercatopyruvate; VitB, Vitamin B6; AOE, Antioxidant enzymes; NRF2, Nuclear factor erythroid-derived 2 -like 2

in blood (Yang et al., 2019). It is no surprise that a vitamin B6 deficiency translates in reduced $\mathrm{H}_{2} \mathrm{~S}$ synthesis (Hughes et al., 2017). CBS is mainly expressed in brain neurons, neurons of the enteric gut nerve system and smooth muscle (Kimura, 2014). CSE is more prominent in the smooth muscles of the vascular system, and is wide spread in other smooth muscle tissues (e.g. of the gut). There is also expression in the brain, albeit that CBS is represented as the dominant enzyme at this site (You et al., 2011). Similar to NO and $\mathrm{CO}, \mathrm{H}_{2} \mathrm{~S}$ is involved in gastro-intestinal (patho-)physiology, including pro- and anti-inflammatory activities, control of motility and vascular tone (Cipriani and Mencarelli, 2011; Medani et al., 2011; Chan and Wallace, 2013; Linden, 2014). Intestinal bacteria are an additional source of $\mathrm{H}_{2} \mathrm{~S}$ in the gut lumen, which might push $\mathrm{H}_{2} \mathrm{~S}$ concentrations locally above the healthy limit, and evokes disease in some cases (Blachier et al., 2019). Allicin is a natural $\mathrm{H}_{2} \mathrm{~S}$ donor simply found in vegetables like garlic and onions (Benavides et al., 2007). Sulfide salt pills are also used, with a preference for $\mathrm{CaS}$ instead of $\mathrm{NaSH}$ due to its stability ( $\mathrm{Li}$ et al., 2009; Wen et al., 2018). There is also a synthetic slow-releasing donor, GYY4137, but this is not yet in the phase of application in humans (Powell et al., 2018; Wen et al., 2018).

In the next section, we summarize the state of knowledge on the interaction between gasotransmitters and the gastrointestinal hormones: gastrin, cholecystokinin (CCK), secretin, motilin, ghrelin, glucagon-like peptide (GLP) -1 and -2 .

\section{GASTRIN}

Gastrin is a peptide hormone released from the G-cells situated mainly in the antrum and less dispersed in the non-antral stomach, small intestine and pancreas (Rehfeld, 1998). The presence of food stimulates the G-cells in different ways:

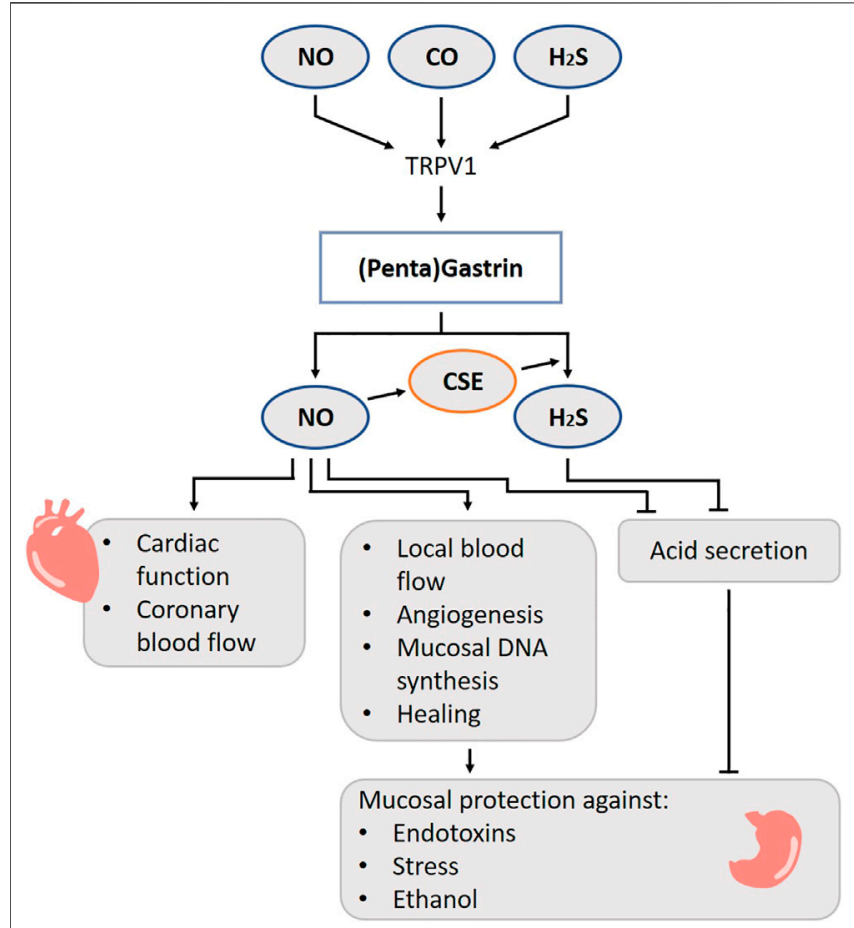

FIGURE 4 | Role of gasotransmitters on gastrin release and its physiological functions. Solid lines are clear evidence-based on blockers and substrate administration. Gaseous molecules may regulate gastrin release via TRPV1. There is a beneficial relation between NO and gastrin leading to hyperemia, increased local blood flow, angiogenesis, mucosal DNA synthesis and increased healing. $\mathrm{NO}$ and $\mathrm{H}_{2} \mathrm{~S}$ governs the gastric acid output. Taken all together, gastrin performs a stomach protecting function via gasotransmitters. $\mathrm{NO}$, Nitric oxide; $\mathrm{CO}$, Carbon monoxide; $\mathrm{H}_{2} \mathrm{~S}$, Hydrogen sulfide; TRPV1, Transient receptor potential vanilloid subtype 1; CSE, Cystathionine gamma-lyase.

directly by sensing proteins and its digested forms (Rehfeld, 1998), by the pyloric antrum (Sugawara et al., 1970), by activation of the vagal nerve and by responding to changes in luminal pH (Chu et al., 1999). Capsaicin, which causes a "burning sensation" and which is present in e.g. chili peppers, stimulates gastrin secretion from isolated human antral glands (Ericson et al., 2009). Capsaicin-sensitive afferent neurons also participate in the secretion of gastrin by luminal alkalization or acidification in a rat model (Nojima et al., 2000). The capsaicin receptor, the transient receptor potential cation channel subfamily $\mathrm{V}$ member 1 (TRPV1), functions as a detector for other chemical and physical stimuli such as a temperature rise, $\mathrm{pH}$ change, mechanical stimulation, osmotic pressure change and gaseous molecules such as NO, $\mathrm{H}_{2} \mathrm{~S}$ and $\mathrm{CO}$ (Takahashi et al., 2012) (Figure 4). Thus, gaseous molecules may regulate gastrin release via TRPV1.

Gastrin stimulates parietal cells to promote acid release during the gastric phase of digestion. It acts both directly on the parietal cell and indirectly via binding onto cholecystokinin 2(CCK2)/ gastrin receptors on enterochromaffin-like cells in the stomach, which in turn release histamine (Rehfeld, 1998). In addition, gastrin is known to cause chief cells to secrete pepsinogen 
(Fiorucci and McArthur, 1990), to increase antral muscle contractions (Cameron et al., 1970), to strengthen antral contractions against the pylorus, and to relax the pyloric sphincter which increases the rate of gastric emptying (Fisher et al., 1973), to induce relaxation of the ileocecal valve (Vadokas et al., 1997), to stimulate pancreatic secretions and gallbladder emptying (Valenzuela et al., 1976), to stimulate cell proliferation in gastrointestinal mucosa (Watson et al., 2006), to play a role in protective activity against ethanol damage of gastric mucosa (Konturek et al., 1995a; Konturek et al., 1995b) and to increase lower esophageal sphincter (LES) tone (Castell, 1978). When these physiological processes do not follow the normal course of events, understanding the governing role of gasotransmitters on these pathways might help to restore the divergence.

One study reported that endogenous NO did not directly modulate acid secretion induced by pentagastrin, a gastrin agonist, in anesthetized rats (Pique et al., 1992). However, there is a body of evidence that favors an inhibitory role of $\mathrm{NO}$ on gastric acid secretion in isolated human gastric glands and in an in vivo rat and dog model (Bilski et al., 1994; Stroff et al., 1994; Berg et al., 2004). In case of a disease, there is often an inhibition of gastric acid secretion, possibly intended as survival mechanism to protect against further degradation of the stomach wall. This phenomenon has been attributed to the presence of endotoxin. In rats, administration of E. Coli endotoxin abolishes the acid secretion induced by pentagastrin. However, after pre-treatment of these rats with both L-NAME and a platelet-activating factor receptor antagonist, the gastric acid output is restored. This suggests that formation of NO may be involved in endotoxininduced inhibition of acid production (Martinez-Cuesta et al., 1992). Besides for endotoxins, a similar response is observed after administration of oxytocin, elevation of body temperature or reduction in blood pressure as proxies for somatic stress in rats (Esplugues et al., 1996). Administration of L-NAME in the dorsal motor nucleus of the vagus nerve reversed the acid-inhibitory effects of aforementioned stimuli. The in vivo action of NO in the rat brainstem in modulation of gastric acid has also been reported by others (Beltrán et al., 1999; García-Zaragozá et al., 2000; Quintana et al., 2001) and seems to be calcium dependent and specifically related to nNOS (Barrachina et al., 1995a; Barrachina et al., 1995b; Esplugues et al., 1996; Uribe et al., 1999).

HO-1 and -2 are expressed in the mucosa of the rat and monkey fundic glands in cells containing the $\mathrm{H}^{+} \mathrm{K}^{+}$-ATPase, markers for parietal cells (Hu et al., 1998; Ueda et al., 2009; Takagi et al., 2016). HO-2 immunopositive cells are also present in the pyloric part of the stomach, although to a lesser extent. The majority of these cells also seem to express gastrin, but not somatostatin (SST) or serotonin (Hu et al., 1998). Whether $\mathrm{CO}$ production has a physiological relevance for parietal cells and gastrin cells is not known to date. More studies are required looking into the effect of $\mathrm{CO}$ on gastrin, histamine and acid release, e.g., using HO-blockers.

$\mathrm{H}_{2} \mathrm{~S}$ governs the gastric acid output to avoid development of ulcers. It contains gastric acid overproduction, releases bicarbonate in the duodenum and stimulates repair after an injury in rat in- and ex vivo models (Wallace, 2012; Mard et al., 2014; Takeuchi et al., 2015). Both CBS and CSE are present in the mucosa of the rat stomach, although only CSE expression is targeted by anti-inflammatory nonsteroidal drugs (Fiorucci et al., 2005). Mard S. and colleagues showed that gastric acid secretion, evoked by pentagastrin or gastric distention, upregulates CSE, and not CBS, expression in rats. NO is an essential step for the translation of CSE mRNA to the enzyme, and thus eventually for $\mathrm{H}_{2} \mathrm{~S}$ production (Mard et al., 2015).

When the need for acid release decreases, other gut peptides are released: SST (Bloom et al., 1974), secretin (Itoh et al., 1975), glucose-dependent insulinotropic polypeptide (GIP), vasoactive intestinal peptide (VIP) (Villar et al., 1976), and calcitonin (Hornum et al., 1976); and all of these exert inhibitory effects on the G-cells.

There is a beneficial interaction between gastrin and NO with respect to preserving mucosal integrity in response to toxins. The protective effects of gastrin on ethanol-induced mucosal damage are eliminated when NO synthesis is blocked and restored when L-arginine is administered in rat models in vivo (Stroff et al., 1994; Konturek et al., 1995a; Konturek et al., 1995b). In the context of gastric ulcers, there is also a beneficial relation between administration of $\mathrm{NO}$ and gastrin concentrations leading to hyperemia, increased local blood flow, angiogenesis, mucosal DNA synthesis and, ultimately, increased healing in rats (Brzozowski et al., 1995; Tatemichi et al., 2003).

In historical experiments, administration of the CCK2R (gastrin receptor) agonist pentagastrin not only increased gastric blood flow, but also affected arterial blood pressure and myocardial contractility through $\mathrm{NO}$ and the parasympathetic system in anesthetized rats and cats (Pawlik et al., 1987; Walder et al., 1990). Stimulation of the CCK1/2R by gastrin-17, one of the two major postprandially released forms of gastrin, stimulates endothelial NO production in porcine coronary arteries (Grossini et al., 2012) and results in a dose-related increase in cardiac function and coronary blood flow (Grossini et al., 1985; Grossini et al., 2011). It is noteworthy, that besides stimulation of CCK1/ $2 \mathrm{R}, \beta 2$-adrenoreceptors-related NO release is likely to be involved in the effects of gastrin on the porcine coronary endothelial cells in vivo (Grossini et al., 2012). Based on these results, we suggest that gastrin may be involved in the increase in cardiac output associated with digestion.

Concerning the effects of NO and gastrin on motility, a small randomized trial showed that the NO-donor molsidomin decreased LES pressure. However, this is not associated with changes in plasma concentrations of gastrin (Brzozowski et al., 1995). In addition, NO does not seem to be involved in the gastrin-induced relaxation of the canine stomach (Schuurkes and Meulemans, 1994; Meulemans et al., 1997).

The HO-2 enzyme is expressed in neurons of the myenteric plexus and submucosal plexus from stomach and jejunum in humans, where the expression pattern with NOS overlaps for $40 \%$ (Miller et al., 2001). CO induces the production of cGMP which may increase cAMP levels by inhibiting phosphodiesterases, eventually leading to a hyperpolarization which relaxes smooth muscles (Wu and Wang, 2005). Normally, NO downregulates the HO-2 expression (Ding et al., 1999), but in case of $\mathrm{O}_{2}$-shortage, the negative feedback on $\mathrm{CO}$ production is no longer present and 
CO takes over several governing functions (Wu and Wang, 2005). $\mathrm{CO}$ is responsible for the nonadrenergic/noncholinergic (NANC) relaxations, although the role of gastrin in this pathway is not known (Watkins et al., 2004).

In rodents, $\mathrm{H}_{2} \mathrm{~S}$ relaxes gastrointestinal muscles (Gallego et al., 2008), such as the pyloric sphincter (Medeiros et al., 2012). Moreover, administration of L-cysteine and NaHS enhances gastric emptying of a liquid meal. Treatment with a CSE antagonist, DL-propargylglycine, blocks the accelerated gastric emptying. In addition, a TRPV1 antagonist also abolishes the effect, implicating that these channels are involved in the induced relaxation of the pylorus muscles. The L-cysteine and NaHS administration cause no changes in acidity in comparison to the placebo, suggesting that gastrin is probably not involved in this effect (Medeiros et al., 2012).

\section{CHOLECYSTOKININ}

CCK is released by enteroendocrine I-cells, located in the duodenal and jejunal mucosa, by luminal exposure to food (French et al., 1995; Geraedts et al., 2010). Fatty acids or their monoglycerides containing twelve or more carbon atoms are the most potent stimuli for CCK release (McLaughlin et al., 1999). Its most important role is in the digestion of fat particles and/or proteins that normally take a long time to be chemically broken down. This is achieved by CCK-induced contraction of the gallbladder, secretion of pancreatic enzymes and relaxation of the sphincter of Oddi (Geenen et al., 1980; Masclee et al., 1989; Schmidt et al., 1991). Furthermore, CCK directly stimulates the suppression of appetite in the brain and inhibits gastric motility and emptying, thereby increasing the time for complete digestion (Chandra and Liddle, 2007). The actions of CCK are mediated by two receptors, designated as CCK1 receptor (CCK1R) and CCK2 receptor (CCK2R). In humans, CCK1Rs are mainly located peripherally such as in the stomach, the intestine, colon, gallbladder muscularis and to a lesser extent in the pancreas (Reubi et al., 1997; Schmitz et al., 2001). CCK1Rs are also expressed in discrete areas in the mouse brain, but in these regions, CCK2Rs dominate (Vialou et al., 2014). In addition, the latter can also be found in the stomach (such as in acid secreting cells) and the pancreas in humans (Nishimori et al., 1999; Schmitz et al., 2001). CCK2 brain receptors exert a complex regulation of dopamine activity in the brain, and thus their involvement in human anxiety states is well documented. Patients with panic disorder are hypersensitive to CCK2R stimulation compared to healthy volunteers (Bradwejn and Koszycki, 2001). CCK stimulates SST release by binding the CCK1Rs on gastric D-cells, thereby indirectly inhibiting gastric acid secretion (Schmitz et al., 2001). CCK receptors are also expressed in neural tissues (Dufresne et al., 2006). Here, CCK acts as a neuromodulator and/or -transmitter and influences processes such as satiety, nociception, and anxiety (Crawley and Corwin, 1994). CCK2R is also known as the gastrin receptor, and this is because gastrin and CCK share their carboxyl-terminal heptapeptide amide, an important region for their biological activity (Miller and Gao, 2008).
Among various physiological actions of CCK, NO has been shown to be involved in intestinal motility, intestinal vasodilation and food intake regulation. Cholecystokinin-8 (CCK8) administration increases the occurrence of transient LES relaxations through the activation of CCK1Rs in anesthetized dogs. Pretreatment with the NOS inhibitor abolishes the effect (Boulant et al., 1994). Impairment of LES sphincter function can lead to gastroesophageal reflux disease (Zerbib et al., 1998). Thus, through a NO-mediated pathway, CCK plays a role in preventing acid reflux to the esophagus in the intestinal phase of the digestive process (Figure 5). Duodenal nutrient infusion initiates relaxation of the proximal stomach. Therefore, it has been hypothesized that a postprandial duodenogastric feedback, including release of CCK, is involved in the control of gastric accommodation. Avoiding the entrance of nutrients in the small bowel eliminates nutritional feedback and hampers gastric accommodation in a nutrient tolerance test (Demarchi et al., 2004; Carbone et al., 2019). Administration of orlistat, a selective lipase inhibitor, decreases plasma CCK levels but does not affect gastric accommodation during a satiety drinking test. Whether CCK actually induces the drop in fundic tone in a NO-dependent fashion has yet to be elucidated (Kindt and Tack, 2006). In dogs, gastric contractility and emptying are suppressed after treatment with a competitive NOS inhibitor (Tanaka et al., 2005). CCK induces contractions of the smooth muscle of the colon by interacting with the CCK1R in humans (Morton et al., 2002). By contrast, CCK2Rs are found to mediate the inhibitory actions of CCK on motor activity in human distal colon muscles strips and evidence exists that this action is NO-dependent, which is also found in rat in vivo experiments and in vitro studies in canine colon cells (Publicover et al., 1993; Takahashi et al., 2005; Fornai et al., 2007).

The CCK-NO system may respond to increased blood flow in the gastrointestinal tract with digestion of nutrients. In isolated bovine cerebral and mesenteric arteries, CCK induces neurogenic vasodilatation by acting on the CCK2R, and this is nNOS dependent (Sánchez-Fernández et al., 2003; Sanchez-Fernandez et al., 2004). This suggests that CCK stimulates nNOS activity and thus NO release (Ruiz-Gayo et al., 2006). CCK mediated splanchnic vasodilatation is also prevented by NOS inhibition (Lovick, 2009). Intravenous administration of CCK8 results in a decrease in the mesenteric vascular resistance and leads to vasodilatation of the pancreatic artery in dogs (Thulin and Olsson, 1973; Chou et al., 1977; Premen et al., 1985; Doi et al., 1990). Moreover, it is likely that the increased blood flow by NO also results in augmented CCK-induced pancreatic secretion of fluid, bicarbonate, and protein in both in vivo and -vitro dog and rat models (Konturek et al., 1993; Patel et al., 1995; Jyotheeswaran et al., 2000). Isolated canine pancreatic arteries, which lack a full innervation, are less sensitive to CCK, which suggests the involvement of neurons (Ruiz-Gayo et al., 2006). The CCK induced vasodilation in the pancreas mainly affects the exocrine part and is less prominent for the endocrine part. It is suggested that the postprandial CCK response improves pancreatic enzyme secretion, while there is a possibility that insulin release toward its targets is enhanced in anesthetized rats (Iwase et al., 2003). Exogenous and endogenous CCK induces 


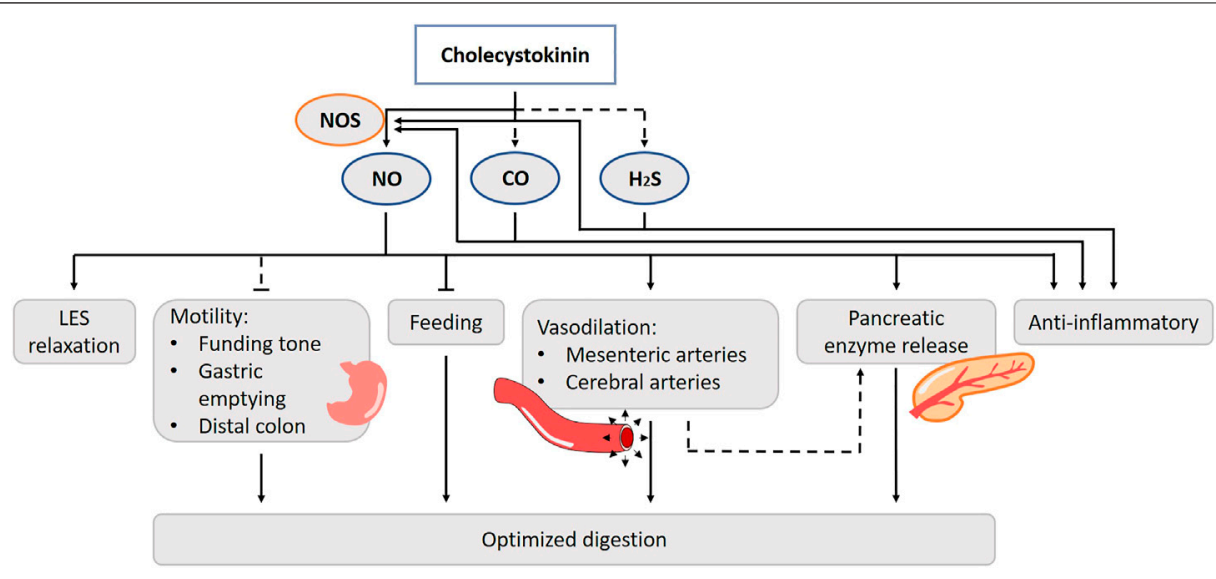

FIGURE 5 | Role of gasotransmitters on cholecystokinin's (CCK) physiological functions. Solid lines are clear evidence-based on blockers and substrate administration. Dotted lines represent first evidence for the presence of the pathway. CCK stimulates nNOS activity and thus NO release. NO is involved in the cholecystokinin effect on LES relaxation, intestinal vasodilation and food intake regulation. The CCK-NO-pathway of intestinal motility has only been hypothesized in literature. CCK anti-inflammatory actions are evoked by reducing vascular and macrophage iNOS-derived $\mathrm{NO}$ production. The involvement of $\mathrm{CO}$ and $\mathrm{H}_{2} \mathrm{~S}$ in these functions have only been suggested, but lack experimental prove. NO, Nitric oxide; CO, Carbon monoxide; $\mathrm{H}_{2} \mathrm{~S}$, Hydrogen sulfide; NOS, Nitric oxide synthase; LES, Lower esophageal sphincter.

gastric mucosal hyperemia in response to sensory nerve stimulation by luminal noxious stimuli such as ethanol or bile (Evangelista et al., 1987; Evangelista and Maggi, 1991; Stroff et al., 1994; Konturek et al., 1995a; Sánchez-Fernández et al., 2003; West et al., 2003). Inhibition of NOS reduces the ability of CCK to augment gastric blood flow in vivo in rats (Stroff et al., 1994; Konturek et al., 1995c; Heinemann et al., 1996). In one in vivo study, CCK increases $\mathrm{Ca}^{2+}$-dependent NOS activity, primarily via eNOS and not via iNOS in rats (West et al., 2003). Controversy exists which CCK receptor is involved in the process of gastric hyperemia and blood flow, as both the CCK1R (Brzozowski et al., 1999; West et al., 2003) and CCK2R (Heinemann et al., 1995) have been suggested in anesthetized rats. Of notice, both receptor subtypes are able to activate the NO/cGMP pathway (Aras and Ekström, 2006; Dufresne et al., 2006).

$\mathrm{NO}$ is involved in the peptide regulation of feeding in the central nervous system, including CCK's. The intake-reducing actions of endogenous CCK depend upon the vagal nerve and the dorsal vagal complex in a rat in vivo model (Sullivan et al., 2007). In mice, administration of CCK inhibits food intake, but fails to do so in nNOS-knockout mice (Morley et al., 2011). CCK is found to co-exist with NOS in rat hypothalamus suggesting that NO works in conjunction with CCK to regulate feeding behavior at a central level (Yamada et al., 1996; Morley et al., 2011). Besides the hypothalamus, CCK and NO are functionally involved in regulatory neurotransmission in other parts of the rat brain including the cortico-striato-pallidal circuitry (Ferraro et al., 2003).

Little is known about the role of $\mathrm{CO}$ or $\mathrm{H}_{2} \mathrm{~S}$ in the CCK up- or downstream pathways. In rat pancreatic acinar cells, both $\mathrm{H}_{2} \mathrm{~S}$ and $\mathrm{CO}$ govern $\mathrm{Ca}^{2+}$ homeostasis and $\mathrm{CO}$ was shown to intervene with the CCK8-induced enzymatic secretions. They stimulate NOS expression and NO production in these cells, although blocking the NO-pathway has no effect on the increased $\mathrm{Ca}^{2+}$ levels for $\mathrm{CO}$, while for $\mathrm{H}_{2} \mathrm{~S}$ the effect is largely abolished (Moustafa and Habara, 2014a; Moustafa and Habara, 2014b).

CCK also has anti-inflammatory actions, possibly by reducing vascular and macrophage iNOS-derived NO production in rat in vivo models (Saia et al., 2013; Zuelli et al., 2014). In lipopolysaccharide (LPS)-stimulated peritoneal macrophages, the inhibition of iNOS mRNA expression by CCK is accompanied by inhibition of the NF- $\kappa$ B signaling pathway and an increase in intracellular cAMP content, activation of the protein kinase A (PKA) pathway and up-regulation of CCK1R in anesthetized rats (Saia et al., 2014). The antiinflammatory effect of CCK may regulate the excessive macrophage activation effect of LPS contained in food. CO has also been suggested as a potential treatment for acute pancreatitis. Serum CCK8 levels are remarkably increased after an LPS-induced inflammation at the site of the lungs. The protective effect of CCK8 is abolished after the treatment with a HO-1 inhibitor, suggesting the in vivo involvement of $\mathrm{CO}$ in rats (Huang et al., 2004). Similar results are found for $\mathrm{H}_{2} \mathrm{~S}$. The lungs are sensitive organs for an endotoxic shock and are therefore more studied. Blocking the CSE activity worsens the acute lung injury (Moustafa and Habara, 2014a). CCK8 induces CSE activity and attenuates the injury in an anesthetized rat model (Tian et al., 2017). More research is needed for other organs such as the pancreas. Under healthy circumstances, HO-1 and HO-2 are not expressed in the exocrine part, while HO-1 expression is induced during a period of inflammation (Moustafa and Habara, 2014a). CCK8 can have an impact on multiple organs by reducing the proinflammatory cytokines in the circulation in an in vivo rat model (Ling et al., 2001). However, there are various issues to consider; e.g. whether CCK also has an organ-protecting effect in humans, whether CCK exhibits an organ-protecting effect at physiological concentrations, and why CCK, which is secreted after eating, has an organ-protecting effect. 
HO-2 is expressed in myenteric neurons, in neuronal cell bodies and in nerve fibers in the gallbladder. Together with NO and VIP, $\mathrm{H}_{2} \mathrm{~S}$ functions as a neurotransmitter to induce muscle relaxation. Exogenous $\mathrm{CO}$ induces a relaxation in dog gallbladder strips, and a specific $\mathrm{HO}$-inhibitor attenuates the neurally mediated relaxation of an electrical field stimulation, which implies a role for endogenous CO. Whether it is involved in the actions of CCK, has yet to be elucidated (Alcon et al., 2001).

\section{SECRETIN}

Secretin is produced in S-cells of the duodenum and jejunum. It is involved in the small bowel $\mathrm{pH}$ regulation through inducing bicarbonate secretion and suppressing gastric acid secretion. The latter is mediated by SST and prostaglandin. In addition, secretin induces gastric relaxation, delays gastric emptying and induces secretion of pancreatic enzymes (i.e., amylase and lipase). The $\mathrm{pH}$ neutralization is important for the activity of these enzymes (Hacki, 1980; Chey and Chang, 2003). The main trigger for secretin release is acid delivered into the duodenal lumen. Digested products of fat and proteins, bile acid and herbal extracts also contribute to its release (Chey and Chang, 2001). Like CCK, the release of secretin along with pancreatic exocrine secretion is controlled through a feedback regulatory mechanism mediated by pancreatic proteases (Green and Lyman, 1972). The expression of the secretin receptor has been demonstrated in a number of organs including the brain (cerebellum, hippocampus and central amygdala) of humans and rodents, pancreas, stomach, kidney as well the biliary epithelium in the liver (Afroze et al., 2013). Besides the important roles of secretin in increasing hepatic and pancreatic secretion of sodium bicarbonate and inhibition of gastrin release, secretin has additional functions. In stomach, secretin stimulates gastric pepsin secretion and suppresses gastric emptying, which facilitates digestion of proteins in duodenum (Vagne and Andre, 1971; Sanders et al., 1983). In the kidney, secretin plays a role in increasing urinary volume and bicarbonate excretion in normal human subjects, which helps to maintain body water homeostasis (Baron et al., 1958; Viteri et al., 1975). In the rodent brain, secretin can act as a central nervous system peptide neurotransmitter (Yang et al., 2004; Nishijima et al., 2006; Yamagata et al., 2008). For this reason, secretin has gained substantial attention as a putative treatment approach to autism and affective disorders, but this remains an area of ongoing controversy (McQueen and Heck, 2002; Boismenu et al., 2004). Secretin also affects the cardiovascular system (Chou et al., 1977). In human, infusion of secretin in both controls and patients with decreased left ventricular function, increased cardiac output, stroke volume and decreased systemic vascular resistance (Gunnes et al., 1983; Gunnes and Rasmussen, 1986).

Although NOS is expressed in $40 \%$ of the myenteric plexus, VIP and not NO, is involved in the gastric relaxation induced by secretin in vivo in rats (Lu and Owyang, 2009). Administration of NO-generating compounds does not affect the release of SST,

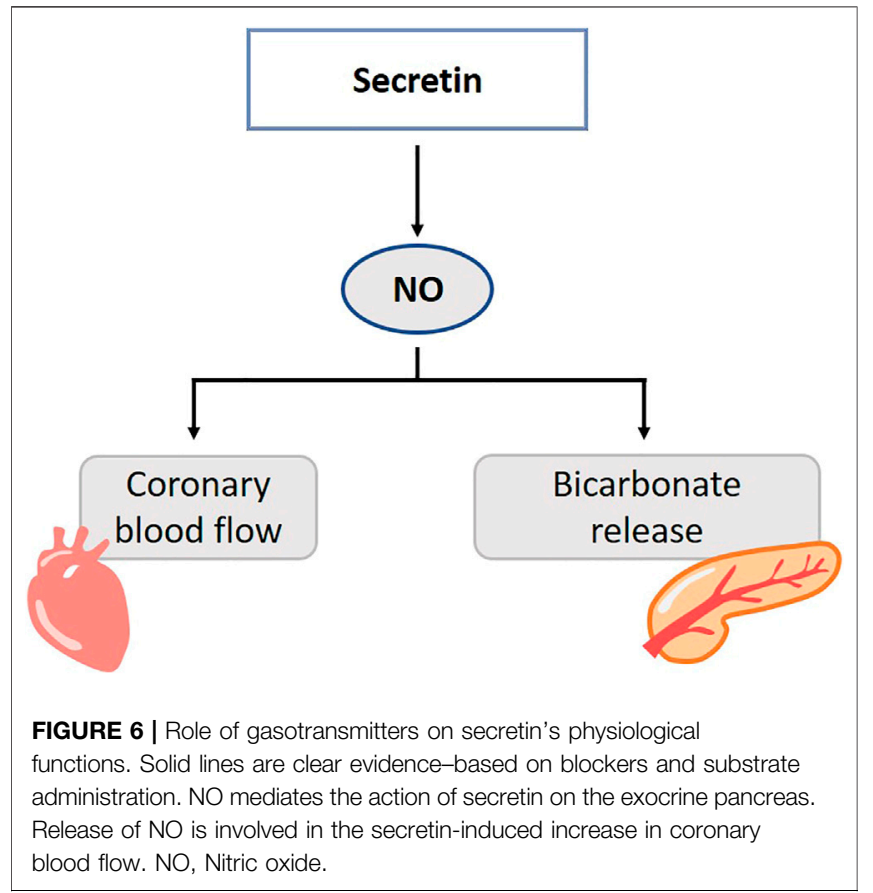

which lays downstream of secretin's suppression of gastric acid release in isolated rat synaptosomes (Kurjak et al., 1996).

In rats and cats, inhibition of NO synthesis in the pancreas results in a dose-dependent decrease of the secretin-stimulated, bicarbonate secretion (Patel et al., 1995; Jyotheeswaran et al., 2000; Konturek et al., 1997). This was restored by L-arginine and NO-inhibition did not affect endogenous secretin plasma levels (Jyotheeswaran et al., 2000). It was suggested that NO mediates the action of secretin on the exocrine pancreas, probably through neuronal pathways, and not the release of secretin (Kirchgessner et al., 1994; Chey and Chang, 2014) (Figure 6). Little is known about the role of $\mathrm{CO}$ and $\mathrm{H}_{2} \mathrm{~S}$ in the secretin pathways. Duodenal acidification is sensed by capsaicin-sensitive sensory neurons, which in their turn induce NO. NO stimulates bicarbonate release via cGMP-dependent kinase $\mathrm{I}$, which is suggested to be responsible for $70 \%$ of the acid-induced bicarbonate release. Endo- or exogenously generated $\mathrm{H}_{2} \mathrm{~S}$ and $\mathrm{CO}$ stimulate bicarbonate secretion in the duodenum of rodents. The stimulatory action of $\mathrm{NO}$ and $\mathrm{CO}$ is mediated by endogenous prostaglandins, while that of $\mathrm{H}_{2} \mathrm{~S}$ is mediated by prostaglandins and NO and also involves sensory neurons (Seidler, 2013; Mard et al., 2016a). Direct evidence of the involvement of secretin in this pathway is lacking. These results rather raise the impression that secretin function and gasotransmitters are not entangled.

In the healthy and diabetic rat excess or lack of NO changes the blood pressure, cardiac and coronary effects of secretin (Sitniewska et al., 2000a; Sitniewska et al., 2000b; Sitniewska et al., 2002). In pigs, release of NO is involved in the secretininduced increase in coronary blood flow (Grossini et al., 2011) (Figure 6). L-NAME decreases vascular permeability of the left ventricle and atria in intact and diabetic rats. Secretin elevates systolic and diastolic blood pressure in in vivo rats, but lack an effect on vascular permeability. Secretin abolishes the NOS- 
inhibition by L-NAME, and restores microcirculation function (Sitniewska and Wiśniewska, 2001).

\section{MOTILIN}

Since recent studies showed that motilin plays a role in the control of hunger and regulation of food intake in humans in both health and disease, the peptide has attracted more attention (Deloose et al., 2019). It stimulates gastrointestinal motility in several mammals, but not in rodents (He et al., 2010), through direct action on the smooth muscle cells and/or activation of the cholinergic or noncholinergic neural pathways in the isolated chicken gut (Kitazawa et al., 2002). Motilin is released by enteroendocrine $\mathrm{M}$-cells in the proximal duodenal region (Wierup et al., 2007). In the fasting state, plasma levels of motilin fluctuate in parallel with phase III contractions of the migrating motor complex (MMC), waves of electrical activity that sweep through the intestines in a regular cycle during fasting (Deloose et al., 2012). Changes in the luminal environment of the duodenum, dietary components, and hormones on motilin release have been reported to affect motilin release (Deloose et al., 2019). Acidification of the duodenum and bile acids stimulate the release of motilin when foods move into the duodenum, and alkalization of the duodenum suppresses it after pancreatic juice secrets into the duodenum in humans (Collins et al., 1981; Svenberg et al., 1984; Qvist et al., 1995). The release of motilin after a meal depends on the nutrient composition of the meal. A small reduction occurs after the administration of glucose, but lipids markedly increase the release of motilin (Mitznegg et al., 1976). Other hormones such as insulin, SST, and secretin reduce motilin levels (Mitznegg et al., 1977; Jenssen et al., 1984; Jenssen et al., 1986). In the gastrointestinal tract, motilin increases the pressure of LES, initiates gastric phase III contractions of the MMC, stimulates gastric emptying, inhibits gastric accommodation and increases rectal compliance in humans (Domschke et al., 1976; Bormans et al., 1987; Peeters et al., 1992; Kamerling et al., 2003; Cuomo et al., 2006). Insulin secretion and gallbladder emptying are both increased by motilin in humans and dogs (Luiking et al., 1998; Suzuki et al., 1998; Suzuki et al., 2003). Finally, motilin also activates regions in the brain involved in the homeostatic and hedonic regulation of food intake in humans (Zhao et al., 2018). These physiological effects of motilin have not been completely elucidated, however it is hypothesized that motilin helps to clean the stomach to receive the next food in the fasted state (Itoh, 1997). This may also explain why motilin causes hunger stimulation (Tack et al., 2016).

Motilin mediates the contractility of smooth muscles in the stomach through the nervus vagus and/or directly through its receptors at this site in human (Itoh, 1997). NO functions as a neurotransmitter for non-adrenergic, non-cholinergic inhibitory neurons and has been suggested to modify the contractile response of motilin in the stomach. NO synthase inhibition potentiates the contractile response of motilin in the chicken proventriculus through reduction of endogenous NO-mediated presynaptic inhibition on neural acetylcholine release (Kitazawa

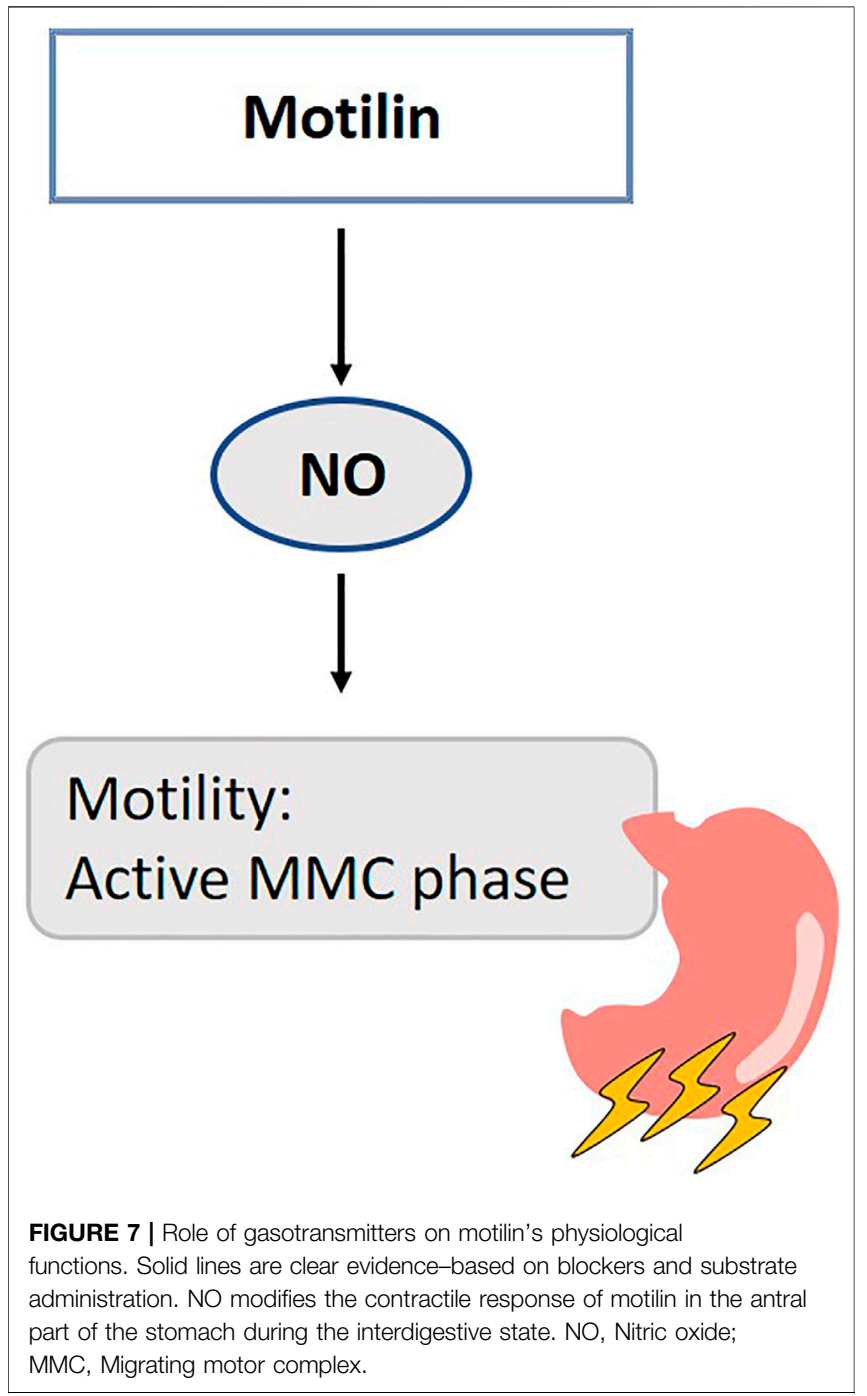

et al., 2002) (Figure 7). Thirty minutes after NOS-inhibition, phase 3-like contractions are initiated in the stomach and duodenum, simultaneous with motilin release in fasted dogs (Sarna et al., 1993; Mizumoto et al., 1997). After this period of activity, the MMC cycle is disrupted, which is suggested to be the consequence of blocked NANC nerves (Sarna et al., 1993). The endogenous motilin release is controlled via a cholinergic pathways independent of the vagus nerve (Mizumoto et al., 1997). In human, L-NMMA induces a premature duodenal phase III within several minutes after administration. Motilin plasma levels were not affected (Halim et al., 2015). These observations led the authors to suggest that L-NMMA provides a direct inhibition of nNOS in the myenteric plexus, independent of endocrine regulators (Halim et al., 2015). The mechanism of action of motilin in dogs is thought to be different from that in humans, so these results need to be interpreted carefully (Peeters et al., 1988). Besides their expression in the stomach and duodenum, motilin receptors are also abundantly present in the central nervous system, in particular the hippocampus in rats (Lange et al., 1986; Guan et al., 2003a; 
Liu et al., 2005) where there is indirect evidence for interaction between NO and motilin (Lu et al., 2015). Nevertheless, the consequences of this finding and the exact mechanisms underlying interaction between motilin and $\mathrm{NO}$ remain to be elucidated.

Both motilin (or the motilin receptor agonist erythromycin) and $\mathrm{H}_{2} \mathrm{~S}$ donors are considered prokinetic drugs for gastric emptying (Peeters et al., 1992; Mard et al., 2016b). The $\mathrm{H}_{2} \mathrm{~S}$ studies were performed in rodents, which do not have a functional motilin or motilin receptor gene. This hypothesis should be worked out in human ex vivo samples from biopsies.

\section{GHRELIN}

Ghrelin is released by P/D1-cells in humans or X/A-like-cells in rats, which are mainly situated in the stomach, and more restricted in the duodenum and pancreas (Kojima et al., 1999; Date et al., 2000). Ghrelin- $\boldsymbol{o}$-acyltransferase enzyme activates about $7 \%$ of the total des-acyl ghrelin production in humans (Marzullo et al., 2004), and stores both forms until secretion is triggered. Ghrelin peaks in the plasma right before a spontaneous meal initiation, and decreases drastically after (Cummings et al., 2001). While lipid loads have no prominent effect on ghrelin, glucose and ingested proteins cause a steep decrease (FosterSchubert et al., 2008). Different factors influence ghrelin baseline values in the plasma. In the fasted state, it is negatively correlated with BMI as a result of the positive energy balance (Shiiya et al., 2002). In addition, the more $H$. pylori thrives and gastric tissue degrades, the lower the ghrelin plasma levels (Tatsuguchi et al., 2004). Lastly, hormones such as testosterone and growth hormone $(\mathrm{GH})$ releasing hormone stimulate ghrelin levels, while insulin, GH, interleukin-1, leptin, SST, urocortin-1, thyroid hormone, CCK, peptide YY (PYY) and melatonin decrease these (Nonogaki, 2008). Ghrelin was first discovered as the growth hormone-releasing peptide and binds the growth hormone secretagogue-receptor 1a (GHSR1a) (Kojima et al., 1999), which is expressed in various regions of the brain (in the pituitary gland for growth hormone secretion, but also in the feeding control regions of the hypothalamus), endothelial, myocardial, pancreatic, renal, adrenal tissues and immune cells (Gnanapavan et al., 2002; Volante et al., 2002; Dass et al., 2003; Tortorella et al., 2003). Besides stimulating GH release and food intake, ghrelin stimulates gastric acid secretion, gastrointestinal motility, modulates energy balance, taste sensation, stress and anxiety, glucose metabolism and has cardiovascular effects (Nakazato et al., 2001). Due to the multiple effects of ghrelin, it is considered a promising therapeutic target for various diseases, including cancer-related cachexia (Garcia et al., 2013). For a comprehensive overview of the effects of ghrelin and the consequences of administration to human, we refer to the literature (Garin et al., 2013; Collden et al., 2017).

Ghrelin acts on the pituitary GHSR to promote the release of $\mathrm{GH}$. In the porcine anterior pituitary, ghrelin activates the NOS/ $\mathrm{NO} / \mathrm{GC} / \mathrm{cGMP}$ signaling pathway, essential for the stimulation of somatotropes (Rodríguez-pacheco et al., 2005). On the other hand, the activation of GHSR1a induces GH release through enhanced phospholipase C activity, protein kinase C and intracellular calcium mobilization in pigs (Chen et al., 1996).

Administration of ghrelin into the arcuate and paraventricular nuclei of the hypothalamus has a potent orexigenic effect and increases body weight by suppressing energy expenditure in rats (Currie et al., 2010). Ghrelin secreted from the stomach is thought to transmit hunger signals via the afferent vagal nerve to the center, and promotes feeding behavior by dual control of activation of anorexic nerves - neuropeptide Y (NPY) and agouti-related protein (AgRP) - and inhibition of feeding behavior suppressive pro-opiomelanocortin (POMC) nerves in rats (Shintani et al., 2001; Kojima and Kangawa, 2005). In the rodent hypothalamus, both NOS and GHSR1a mRNA are expressed ( $\mathrm{Ng}$ et al., 1999; Zigman et al., 2006). In mice, the intracerebroventricular administration of L-NAME results in an attenuated ghrelin stimulants on food intake (Gaskin et al., 2003). Moreover, in NOS knockout mice the administration of ghrelin does not result in increased food intake (Morley et al., 2011). NO is reported as a signaling molecule in neurons, neuropeptide regulation and stimulates feeding in many species (Morley et al., 2011; Han et al., 2013). Although a direct NO-mediated pathway by ghrelin has not been proven yet, these data suggest that reactive oxygen species may regulate food intake through modulation of the NO-bioavailability.

Ghrelin release is suppressed for a long time after a high protein meal (Foster-Schubert et al., 2008). The amino acid L-cysteine, which is a $\mathrm{H}_{2} \mathrm{~S}$ donor, suppresses ghrelin release from the rat stomach, and reduces appetite. On the other hand, direct inhibition of $\mathrm{H}_{2} \mathrm{~S}$ synthesis stimulates ghrelin secretion (Figure 8). Ghrelin cells colocalize with $\mathrm{H}_{2} \mathrm{~S}$ producing enzyme CSE. There seems to be an interplay between these two factors, which provides us of new ideas for treatments e.g., a diet enriched of $\mathrm{H}_{2} \mathrm{~S}$ precursors or sulfur-rich prebiotics to affect ghrelin levels and appetite in mice (Slade et al., 2018).

One of the first established functions of ghrelin were the stimulation of gastric motility and acid secretion (Masuda et al., 2000). Ghrelin is thought to exert these effects primarily via pathways mediated by the vagus nerve (Date et al., 2002). This involves activation of GSHR1a on vagal afferent neurons. In rats, exogenous ghrelin administration increases gastric acid output, mucus content and total plasma nitrite levels, while these effects are inhibited by L-NAME (Bilgin et al., 2008).

In animal studies, ghrelin has a protective effect of the gastric mucosa. In an ischemia/reperfusion experiment using rats, the addition of ghrelin accelerates healing in part by stimulating blood flow and hyperemia mediated by NO (Konturek et al., 2006). Of interest, inhibition of NOS by L-NAME and sensory denervation by capsaicin, but not vagotomy, prevents ghrelin's gastroprotective effects of ethanol-induced ulcers in rodents (Sibilia et al., 2003). HO-1, and thus presumably CO, is also involved in the ghrelin-mediated gastroprotection (Allam and ElGohary, 2017) (Figure 8).

Ghrelin has well-documented cardiac beneficial effects, including protection from ischemia/reperfusion injury, attenuation of left ventricular remodeling following myocardial infarction, and improvement of left ventricular function (Virdis et al., 2016). At the level of blood vessels, ghrelin has a significant 


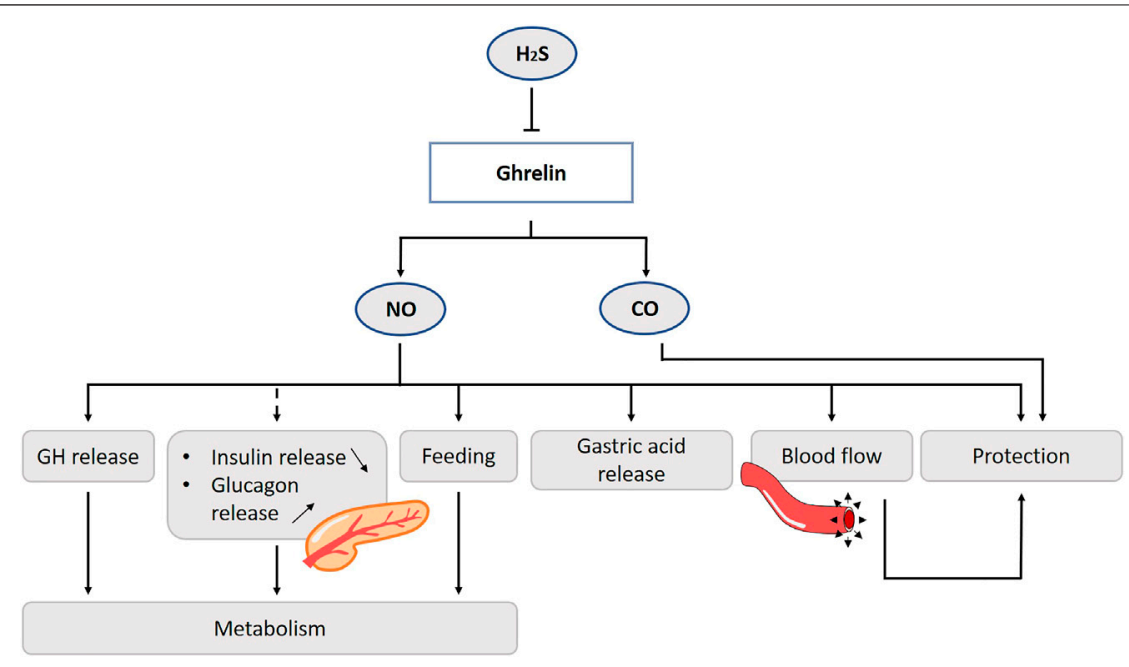

FIGURE 8 | Role of gasotransmitters on ghrelin release and its physiological functions. Solid lines are clear evidence-based on blockers and substrate administration. Dotted lines represent first evidence for the presence of the pathway. The amino acid $\mathrm{L}$-cysteine, which is a $\mathrm{H}_{2} \mathrm{~S}$ donor, suppresses ghrelin release from the stomach. Ghrelin promotes the release of GH via activation of the NOS/NO/GC/cGMP-signaling pathway. Ghrelin also promotes feeding behavior and stimulates gastric motility and acid secretion via the NO-pathway. No direct evidence is found to date for the involvement of NO in the ghrelin-glycemic effect. Ghrelin protects the gastric mucosa, by stimulation of the blood flow and hyperemia mediated by NO. CO is also involved in the ghrelin-mediated gastroprotection. NO, Nitric oxide; CO, Carbon monoxide; $\mathrm{H}_{2} \mathrm{~S}$, Hydrogen sulfide; GH, Growth hormone; NOS, Nitric oxide synthase; GC, Guanylyl cyclase; cGMP, Cyclic guanosine monophosphate.

impact on vascular function. In endothelial cells and in intact vessels, ghrelin stimulates the phosphorylation of eNOS at Ser1177, and not Thr-495 which would inactivate the activity in vitro (Iantorno et al., 2007; Xu et al., 2008; Dudzinski et al., 2006). This action of ghrelin involves signaling through GHSR1a, PI 3-kinase, Akt, and eNOS (Iantorno et al., 2007). In addition, there is evidence that the AMP-activated protein kinase (AMPK) is also a mediator for ghrelin activation of eNOS (Xu et al., 2008). Using a GHSRla knockdown model abolishes the ghrelin influence on endothelial cells (Chen et al., 2013). The activation of eNOS by ghrelin potentiates the NOmediated relaxation of vascular smooth muscle and diminishes the production of reactive oxygen species in reaction to endothelial injury (Iantorno et al., 2007; Xu et al., 2008; Hedayati et al., 2009) (Figure 8). In patients with metabolic syndrome, administration of ghrelin leads to an increase in NO bioactivity and improved endothelial function (Tesauro et al., 2005; Tesauro et al., 2009). It should be noted that some studies suggest that the vasomotor actions of ghrelin are NOindependent in humans and rats (Okumura et al., 2002; Wiley and Davenport, 2002; Shinde et al., 2005). In healthy men, an intra-arterial bolus of ghrelin increases forearm vasodilatation in a dose-dependent manner but this effect is NO-independent (Okumura et al., 2002). Here, the administration of ghrelin does not alter either plasma insulin-like growth factor-1 (IGF-1) or the NO second messenger, cGMP, but decreases plasma norepinephrine. These observations might implicate the involvement of other mechanisms, i.e., the autonomic nervous system. On the other hand, in aforementioned experiment the L-NMMA was only infused for $5 \mathrm{~min}$ leaving the possibility that eNOS activity is incompletely inhibited.
It is conceivable that the inhibitory effect of ghrelin on insulin and stimulatory on glucagon release are mediated by nNOS in pancreatic rat cells (Qader et al., 2005). In the vascular endothelium, ghrelin and insulin share the PI 3-kinase/ phosphoinositide-dependent kinase-1/Akt/eNOS signaling pathway in human (Montagnani et al., 2002; Iantorno et al., 2007). This might account for some of the beneficial effects of ghrelin on metabolic and cardiovascular disease. However, there is controversy about whether ghrelin stimulates or suppresses insulin secretion. This may be due to differences in reactivity depending on animal species or experimental design, so caution should be taken in the interpretation (Dezaki et al., 2004).

Ghrelin exhibits antioxidant effects in many organs, such as heart, pancreas and lung (Suzuki et al., 2011). In rats, injection of ghrelin results in enhanced hepatic expression of antioxidant enzymes (Dobutovic et al., 2014). Together with observations of increased plasma ghrelin concentrations during systemic oxidative stress (Okumura et al., 2002; Bouros et al., 2006; Guzik and Harrison, 2006; Liu et al., 2006) this lead to the suggestion ghrelin could have positive effects on oxidative injury (Suzuki et al., 2011). In rats, treatment with ghrelin after occlusion of the middle cerebral artery results in a decrease in cerebral TNF- $\alpha$, IL-6, neutrophil trafficking, matrix metalloproteinase 9 , nitrotyrosine, and nNOS gene expression. Ghrelin's protective effect is abolished in vagatomized rats, suggesting the involvement of the vagus nerve (Cheyuo et al., 2011).

\section{GLUCAGON-LIKE PEPTIDE 1}

Glucagon-like peptide 1 (GLP-1) is released from L-cells, situated in the ileum and colon (Eissele et al., 1992). In response to the ingestion of dietary carbohydrates or fat, GLP-1 is released and 


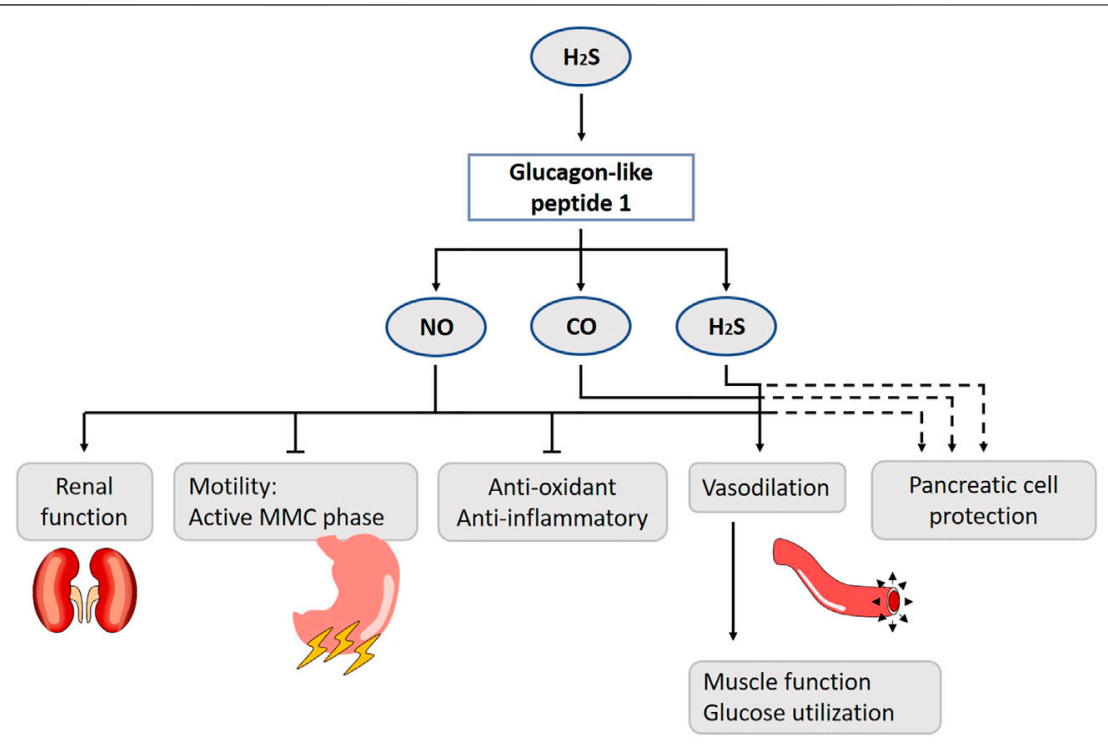

FIGURE 9 | Role of gasotransmitters on glucagon-like peptide 1 (GLP-1) release and its physiological functions. Solid lines are clear evidence-based on blockers and substrate administration. Dotted lines represent first evidence for the presence of the pathway. $\mathrm{H}_{2} \mathrm{~S}$ stimulates GLP-1 release. The suppression of gut motility, reduction of nephropathy risk factors, increase of muscle microvasculature, reduction of the number of reactive oxygen species and production of vasoconstrictive mediators are GLP-1 effects mediated by NO. $\mathrm{H}_{2} \mathrm{~S}$ and $\mathrm{CO}$ also contribute to the vasodilation. It has been suggested that the gasotransmitters play a protective role to govern pancreatic function in case of glucotoxicity. NO, Nitric oxide; $\mathrm{CO}$, Carbon monoxide; $\mathrm{H}_{2} \mathrm{~S}$, Hydrogen sulfide; MMC, Migrating motor complex.

functions as incretin and anorexigenic hormone (Layer et al., 1995). Non-nutrient stimulators of GLP-1 release are the neuromodulators acetylcholine and gastrin-releasing peptide. Peripheral hormones that participate in energy homeostasis, such as leptin, are implicated in the regulation of GLP-1 release (Lim and Brubaker, 2006). Leptin stimulates GLP-1 release from the human and rodent $\mathrm{L}$-cell, and this effect is abolished in leptin-resistant obese mice (Anini and Brubaker, 2003). GIP regulates proglucagon-derived peptide secretion in both in vivo and in vitro rat models (Lim et al., 2009). In the pancreas, GLP-1 enhances insulin release in the presence of high glucose levels in the blood and inhibits glucagon release (Holst, 2007). It suppresses gut motility, resulting in slower entry of the carbohydrates into the small bowel. GLP-1 increases satiation and therefore governs meal size. Numerous studies have shown that GLP-1 levels after a meal are reduced in subjects with type 2 diabetes and obesity (Toft-Nielsen et al., 2001; Anini and Brubaker, 2003). GLP-1 agonists, such as liraglutide, are used as a treatment for these pathologies (Meece, 2017). GLP-1 was discovered in 1979 (Lund, 2005), and after 30 years of research, it has proven to have a broad range of functions, being an incretin, an anorexigenic peptide, decreasing gut motility, but also received more attention recently for its cardiac functions (Lim and Brubaker, 2006; Sun et al., 2015). Many of these functions are in overlap with those of $\mathrm{NO}, \mathrm{H}_{2} \mathrm{~S}$ and CO.

$\mathrm{H}_{2} \mathrm{~S}$ is produced in the colon by sulphate-reducing bacteria, and stimulates GLP-1 release. Considering its short half-life time, it will stimulate nearby L-cells in the colon rather than ileal L-cells after transport in the plasma (Pichette et al., 2017). Four weeks treatment with chondroitin sulfate increases $\mathrm{H}_{2} \mathrm{~S}$ production, enhances GLP-1 and insulin secretion, improves oral glucose tolerance and reduces food consumption (Pichette et al., 2017) (Figure 9). Although NOS is expressed in brush cells - luminal sensors adjacent to enteroendocrine cells -, no direct evidence for NO or CO's involvement has been found (Sternini et al., 2008).

GLP-1 slows gastric emptying, inhibits the active antral MMC phases and prolongs small bowel transit time. It is able to cross the blood-brain barrier (Kastin et al., 2002) and a high density of GLP-1 receptors is present in the vagal circuits in the brainstem (Shimizu et al., 1987; Göke et al., 1995). As such, one could hypothesize that peripherally released GLP-1 functions as a classic hormone by migrating to the central nervous system where it acts on the brainstem. It seems more likely that the brainstem vagal circuits are affected by GLP-1, after activation of gastro-intestinal stimuli (Shimizu et al., 1987). A 1-2 pmol $/ \mathrm{kg}^{-1}$ GLP-1 infusion prolongs the MMC cycle length and abolishes its active antral phase by NO. With a dose of $10 \mathrm{pmol} / \mathrm{kg}^{-1}$, the effect becomes NO-independent in conscious rats (Tolessa et al., 1998; Tolessa et al., 2001). A GLP-1 analogue, LY315902, also decreases gut motility via the NO-pathway in mice (Rotondo et al., 2011).

GLP-1 is mainly known as an incretin. Literature about the role of gasotransmitters in the GLP-1-insulin release is contradictory. At first sight, it seems like the gasotransmitters have a protective role to govern pancreatic function in case of glucotoxicity. Under normal circumstances, the inducible $\mathrm{HO}$ variant is not present in rat beta cells, although in obese rats HO-1 seems to be upregulated (Lundquist et al., 2003). Similar results are shown for iNOS, which is normally only expressed as response to an inflammatory agent, and clearly, an episode of hyperglycemia $(20 \mathrm{mmol} / \mathrm{L})$ is considered stressful for the pancreatic beta cell. GLP-1 induces a cAMP/PKA-pathway inhibiting the expression of iNOS, and prevents beta cell 
apoptosis (Jimenez-Feltstrom et al., 2005). For $\mathrm{H}_{2} \mathrm{~S}$, only CBS is expressed under normal glucose levels in the mouse beta cells, while CSE is induced by hyperglycemia (Beltowski et al., 2018). $\mathrm{H}_{2} \mathrm{~S}$ inhibits insulin secretion by the activation of ATP-sensitive potassium channels, but only in the presence of glucose. Furthermore, it affects beta cell survivability, although the literature is inconsistent on whether it induces apoptosis or in contrast protects these cells (Pichette and Gagnon, 2016; Beltowski et al., 2018). Diabetic animal models or patients have lower $\mathrm{H}_{2} \mathrm{~S}$ blood concentrations (Suzuki et al., 2017). More research should be performed using $\mathrm{H}_{2} \mathrm{~S}$-donors as treatment. $\mathrm{H}_{2} \mathrm{~S}$ has roles in glycemia control beyond insulin, as it plays a role in the liver, muscles and even fat tissue, but this is discussed in more detail in the literature (Pichette and Gagnon, 2016; Beltowski et al., 2018).

GLP-1 receptor agonists have hypotensive actions (Sun et al., 2015). The potential mechanism may be directly mediated via GLP-1 receptor activation on blood vessels and kidney, including improvement of endothelial function, vasodilatation, and natriuresis (Gutzwiller et al., 2004; Nyström et al., 2004; Lorber, 2013; Sun et al., 2015). GLP-1 receptors are expressed in the arteries, glomeruli, and proximal tubules of the kidney (Schlatter et al., 2007; Crajoinas et al., 2011). In human and rodent studies, activation of these receptors results in diuresis, natriuresis and renal vasodilatation (Moreno et al., 2002; Thomson et al., 2013). Several studies established that the effects of GLP-1 reduce risk factors of nephropathy, including hypertension and albuminuria, and lead to renoprotection. As an underlying mechanism, stimulation of the GLP-1 receptor by the GLP-1 agonist exenatide results in an increased glomerular filtration rate, urinary flow rate and urinary prostaglandin E2 and NO degradation products. Pre-treatment with L-NMMA reduces urinary NO degradation products and the impact of exenatide on glomerular filtration rate and urinary flow rate by $50 \%$, implying that NO mediates a part of the renal hemodynamic actions of exenatide in anesthetized rats (Thomson et al., 2017).

Several studies demonstrated that administration of GLP-1 analogues increases NO production in endothelial cells and improves endothelium-dependent vasodilatation in rats (Han et al., 2012; Sélley et al., 2014; Green et al., 2008) (Figure 9). In overnight-fasted male rats, continuous infusion of GLP-1 acutely increases muscle microvasculature, which is associated with increased muscle glucose utilization, plasma concentrations of NO, muscle interstitial oxygenation and muscle insulin clearance/uptake (Chai et al., 2012). Co-infusion of L-NAME abolishes this effect, suggesting that GLP-1 acts via a NOdependent mechanism. From a mechanistic point of view, GLP-1 increases PKA activity and stimulates eNOS's phosphorylation at Ser $(1,177)$ cultured endothelial cells (Dong et al., 2013). The incubation of human umbilical veins with liraglutide promotes eNOS expression (Dai et al., 2013). Furthermore, the dipeptidyl peptidase-4 (DPP-4) inhibitor sitaglipitin is shown to enhance eNOS phosphorylation through the cAMP/PKA pathway by augmenting GLP-1 activity in human coronary artery endothelial cells (Matsubara et al., 2012). These findings suggest that activation of the GLP-1 receptor results in an elevated production of cAMP, activation of
PKA and, subsequently, eNOS and the formation of NO. The latter can enhance endothelium relaxation through stimulation of soluble GC to increase cGMP in vascular smooth muscle cells (Liu et al., 2015). In addition to PKA activation, AMPK and Akt may also be involved in this process. Exenatide is found to stimulate proliferation of human coronary artery endothelial cells through PKA-PI3K/Akt-eNOS activation pathways (Erdogdu et al., 2010), and GLP-1 receptor agonists are able to stimulate eNOS activation and NO production through AMPK phosphorylation in humans (Krasner et al., 2014; Koska et al., 2015). This may be the direct result of AMPK on eNOS, or an indirect effect by activation of uncoupling protein-2 and subsequently reducing the amount of reactive oxygen species and production of vasoconstrictive mediators (Liu et al., 2015; Tang et al., 2016). In contrast, there is also evidence that NO is not involved in the effects of GLP-1 on endothelium-dependent vasodilatation. While infusion of GLP-1 relaxes the isolated rat femoral artery and the specific GLP-1 receptor antagonist exendin (9-39) completely inhibits this, the inhibition of NO does not (Nystrom et al., 2005). In healthy overweight men, the acute infusion of exenatide increases capillary perfusion in the skin, independent of NO (Smits et al., 2015). These discrepancies in NO-dependency may be a result of differences in study design, species, and types of vasculature or peptide used in these experiments. It has been suggested that increased secretion of atrial natriuretic peptide or diuretic effects are also prominently involved (Ryan and Acosta, 2015).

Besides $\mathrm{NO}, \mathrm{H}_{2} \mathrm{~S}$ and $\mathrm{CO}$ also contribute to the vasodilator effect of GLP-1 (Figure 9). In one study, exenatide causes a dose-dependent relaxation in isolated rat thoracic aorta (Sélley et al., 2014). Comparing the effects of the gasotransmitters leading to vasodilatation, $\mathrm{H}_{2} \mathrm{~S}$ had the most remarkable. The cAMP/cGMP-PKA/PKG pathway is identified as an important mediator of the effects of the gasotransmitters. Inhibition of ATP-sensitive voltage-gated calcium-activated large conductance potassium channels, KCNQtype voltage gated potassium channels and, foremost, the $\mathrm{Na} / \mathrm{Ca}$ exchanger decreases the vasodilatation evoked by exenatide. Taken together, this study identified possible cascades of GLP-1 leading to vasodilation and emphasizes the fact that, besides $\mathrm{NO}$, other gaseous transmitters are involved in this process. To the best of our knowledge, this finding has not yet been confirmed by other studies.

The other effects of GLP-1 have been suggested to be organ protective effects due to antioxidant and anti-inflammatory effects, which may also involve effects of NO. Treatment of streptozocin-induced diabetic rats with vildagliptin, inhibitor of DPP-4, which inactivates GLP-1, reduces plasma TNF- $\alpha$ concentration and decreases $\mathrm{NO}$ concentration in serum and pancreatic homogenates compared with untreated diabetic rats (Akarte et al., 2012). Linagliptin, another DPP-4 inhibitor, decreases superoxide dismutase levels and increases NOS levels in hemodialysis patients (Kimura et al., 2016).

\section{GLUCAGON-LIKE PEPTIDE 2}

GLP-2 is a 33 amino acid peptide which is also produced by L-cells. Only $5-10 \%$ of the nutrients reach the distal part of the 


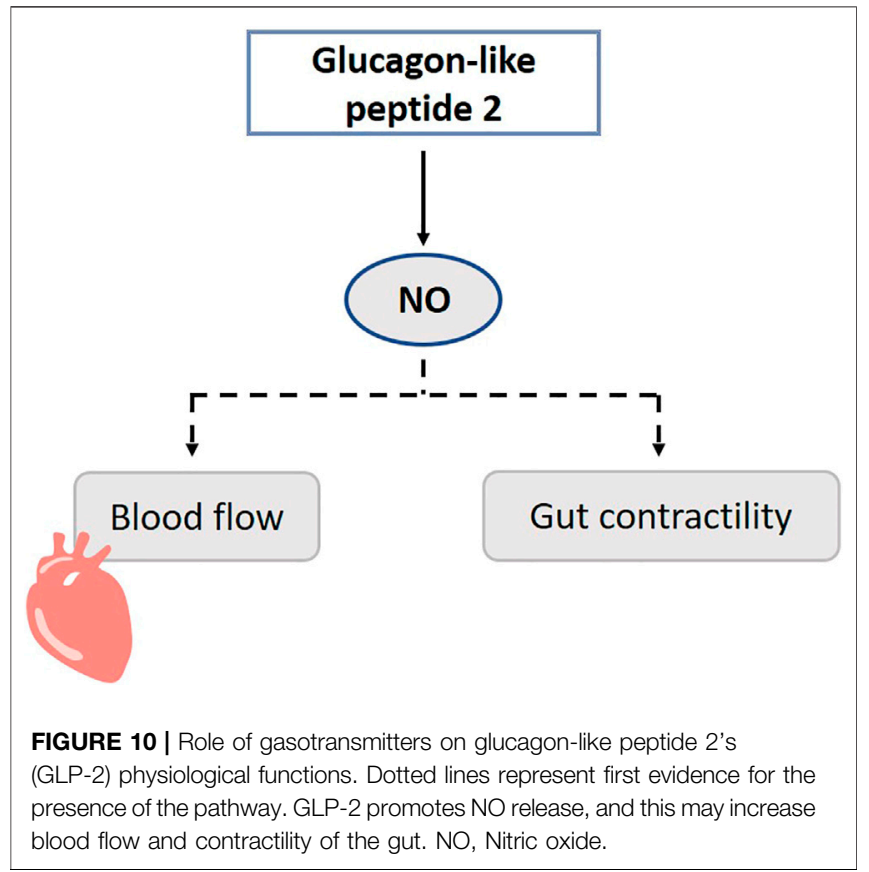

small intestine unabsorbed. In humans, GLP-2 secretion increases in response to exposure to unabsorbed isocaloric meals rich in carbohydrate or fat. Protein rich meals are poor stimulants (Xiao et al., 1999; Thulesen, 2004). GLP-2 plasma levels decrease in response to a fasting period (Drucker and Yusta, 2014). Following nutrient-induced release, GLP-2 effects are mediated by the G-protein-coupled GLP-2 receptor (GLP-2R) which is expressed in the GI-tract to enteroendocrine cells, subepithelial myofibroblast cells, and in the neurons of the enteric nervous system (Guan et al., 2006). GLP-2 has various physiological effects, including stimulation of growth and repair of intestinal epithelium, maintenance of mucosal integrity, upregulation of nutrient absorption, slowing of gastric emptying, reduction of gastric secretions, as well as effects on blood flow and blood pressure, bone resorption inhibitory effects and suppression of food intake (Dubé and Brubaker, 2007; Janssen et al., 2013). Understanding the GLP2 pathways and developing compounds to manipulate the downstream pathway accordingly can lead to new treatments, especially as pre-clinical models: post-operative ileus, GI mucositis and conditions of altered intestinal permeability. The problem however is the short half-life time of GLP-2 (Salaga et al., 2017).

Infusion of GLP-2 acutely and dose-dependently increases intestinal blood flow, which is important for example to improve nutrient absorption. GLP-2Rs are co-localized with eNOS, nNOS and acetylcholine immune-responsive neurons in the myenteric and submucosal neurons of the small intestine. GLP-2 upregulates eNOS expression and stimulates NO release (Guan et al., 2006) (Figure 10). In the colon, activation of the GLP-2R rather antagonizes acetylcholine function and is NO-independent (Guan et al., 2003b; Amato et al., 2010). In rats, GLP-2 infusion increases blood flow in the superior mesenteric artery, but not in the inferior mesenteric or carotid artery. Only a higher dose of L-NAME can partly block the increased blood flow (Bremholm et al., 2009). It must be mentioned that rats are less sensitive for GLP-2 in comparison to mice. Besides inducing a local intestinal increase of blood flow, GLP-2 increases glucose uptake, eNOS mRNA and phosphorylation (eNOS-Ser1117) (Guan et al., 2003b; Guan et al., 2006). The effect of GLP-2 on contractility of the gut is also believed to act via the NO-mediated pathway in the myenteric plexus (Cinci et al., 2011).

In cisplatin treated mice, GLP-2 is able to counteract both the mucosal gastric fundus damage, and the neuropathy, respectively by preventing the epithelium thickness decrease and by protecting nNOS neurons (Pini et al., 2016). This data suggests that GLP-2 plays a role in maintenance in myenteric neurons including nNOS neurons. GLP-2 enhances the expression of iNOS through stimulating the activity of TGF $\beta$ Smad2/3 signaling in osteoclasts in vitro, which may contribute to the inhibition of the proliferation of osteoclasts and which may provide potential therapeutic targets for the treatment of osteoporosis (Lu et al., 2018).

Although GLP-2 is shown to promote NO release, the primary relevance of the NO-dependent signaling of GLP-2 seems to be restricted (Cinci et al., 2011; Moloudi et al., 2011). It is hypothesized that this is also a permissive factor for other functions of GLP-2 such as intestinal growth (Dubé and Brubaker, 2007). Besides NO, several other downstream mediators of GLP-2 are known, including IGF-1 and -2, keratinocyte growth factor, and VIP (Rowland and Brubaker, 2011). It should be considered that the Ser1177 is also a phosphorylation site for Akt, and Akt is a downstream kinase of e.g. the IGF-1 receptor.

\section{SUMMARY}

Gut peptides are important regulators for several physiological processes ranging from muscles contractions or relaxations, systemic or local blood flow, anti-inflammatory actions, feeding behavior, glucose metabolism and many more. In the case of aberrant peptide production, the system becomes disturbed and a therapy needs to be started. The development of drugs targeting peptide receptors is a challenging process. Gaseous neurotransmitters are important for intracellular signaling, and increasing evidence emerges that these are involved in gut peptide release and their physiological functions. These small molecules may be easier to target for pharmacological intervention once their pathways to alter gut peptide signaling are better understood. A major challenge will be the widespread influence of gasotransmitters, in -and outside the gastrointestinal tract, which may thus be associated with loss of organ or process selectivity.

\section{AUTHOR CONTRIBUTIONS}

WV: detailed manuscript writing and finalization, literature research, figures HG: early draft, literature research HM: detailed manuscript writing and finalization, literature research 
AB: early draft, literature research JT: detailed manuscript writing and finalization, literature research PD: early draft, literature research.

\section{REFERENCES}

Abshagen, U. W. (1992). Pharmacokinetics of Isosorbide Mononitrate. Am. J. Cardiol. 70 (17), 61G-6G. doi:10.1016/0002-9149(92)90028-w

Afroze, S., Meng, F., Jensen, K., McDaniel, K., Rahal, K., Onori, P., et al. (2013). The Physiological Roles of Secretin and its Receptor. Ann. Transl Med. 1 (3), 29. doi:10.3978/j.issn.2305-5839.2012.12.01

Akarte, A. S., Srinivasan, B. P., Gandhi, S., and Sole, S. (2012). Chronic DPP-IV Inhibition with PKF-275-055 Attenuates Inflammation and Improves Gene Expressions Responsible for Insulin Secretion in Streptozotocin Induced Diabetic Rats. Eur. J. Pharm. Sci. 47 (2), 456-463. doi:10.1016/j.ejps.2012.07.003

Alcon, S., Morales, S., Camello, P. J., Salido, G. M., Miller, S. M., and Pozo, M. J. (2001). Relaxation of Canine Gallbladder to Nerve Stimulation Involves Adrenergic and Non-adrenergic Non-cholinergic Mechanisms. Neurogastroenterol Motil. 13 (6), 555-566. doi:10.1046/j.13652982.2001.00286.x

Allam, M. M., and El-Gohary, O. A. (2017). Gastroprotective Effect of Ghrelin against Indomethacin-Induced Gastric Injury in Rats: Possible Role of Heme Oxygenase-1 Pathway. gpb 36 (3), 321-330. doi:10.4149/gpb_2016056

Amato, A., Rotondo, A., Cinci, L., Baldassano, S., Vannucchi, M. G., and Mulè, F. (2010). Role of Cholinergic Neurons in the Motor Effects of Glucagon-like Peptide-2 in Mouse colon. Am. J. Physiology-Gastrointestinal Liver Physiol. 299 (5), G1038-G1044. doi:10.1152/ajpgi.00282.2010

Anini, Y., and Brubaker, P. L. (2003). Role of Leptin in the Regulation of Glucagonlike Peptide-1 Secretion. Diabetes 52 (2), 252-259. doi:10.2337/ diabetes.52.2.252

Aras, H. Ç., and Ekström, J. (2006). Pentagastrin-induced Protein Synthesis in the Parotid Gland of the Anaesthetized Rat, and its Dependence on CCK-A and -B Receptors and Nitric Oxide Generation. Exp. Physiol. 91 (4), 673-679. doi:10.1113/expphysiol.2006.033639

Baron, D. N., Newman, F., and Warrick, A. (1958). The Effects of Secretin on Urinary Volume and Electrolytes in normal Subjects and Patients with Chronic Pancreatic Disease. Experientia 14, 30-32. doi:10.1007/bf02159660

Barrachina, M. D., Calatayud, S., Moreno, L., Martínez-Cuesta, M. A., Whittle, B. J. R., and Esplugues, J. V. (1995). Nitric Oxide and Sensory Afferent Neurones Modulate the Protective Effects of Low-Dose Endotoxin on Rat Gastric Mucosal Damage. Eur. J. Pharmacol. 280 (3), 339-342. doi:10.1016/0014-2999(95) 00286-t

Barrachina, M. D., Whittle, B. J. R., Moncada, S., and Esplugues, J. V. (1995). Endotoxin Inhibition of Distension-Stimulated Gastric Acid Secretion in Rat: Mediation by NO in the central Nervous System. Br. J. Pharmacol. 114 (1), 8-12. doi:10.1111/j.1476-5381.1995.tb14898.x

Beltowski, J., Wojcicka, G., and Jamroz-Wisniewska, A. (2018). Hydrogen Sulfide in the Regulation of Insulin Secretion and Insulin Sensitivity: Implications for the Pathogenesis and Treatment of Diabetes Mellitus. Biochem. Pharmacol. 149, 60-76. doi:10.1016/j.bcp.2018.01.004

Beltrán, B., Barrachina, M. D., Méndez, A., Quintero, E., and Esplugues, J. V. (1999). Synthesis of Nitric Oxide in the Dorsal Motor Nucleus of the Vagus Mediates the Inhibition of Gastric Acid Secretion by central Bombesin. Br. J. Pharmacol. 127 (7), 1603-1610. doi:10.1038/sj.bjp.0702717

Benavides, G. A., Squadrito, G. L., Mills, R. W., Patel, H. D., Isbell, T. S., Patel, R. P., et al. (2007). Hydrogen Sulfide Mediates the Vasoactivity of Garlic. Proc. Natl. Acad. Sci. 104 (46), 17977-17982. doi:10.1073/pnas.0705710104

Berg, A., Redeen, S., Ericson, A. C., and Sjostrand, S. E. (2004). Nitric Oxide-An Endogenous Inhibitor of Gastric Acid Secretion in Isolated Human Gastric Glands. BMC Gastroenterol. 4, 16. doi:10.1186/1471-230x-4-16

Bescós, R., Sureda, A., Tur, J. A., and Pons, A. (2012). The Effect of Nitric-OxideRelated Supplements on Human Performance. Sports Med. 42 (2), 99-117. doi:10.2165/11596860-000000000-00000

Bilgin, H., Tumer, C., Diken, H., Kelle, M., and Sermet, A. (2008). Role of Ghrelin in the Regulation of Gastric Acid Secretion Involving Nitrergic Mechanisms in Rats. Physiol. Res. 57 (4), 563-568. doi:10.33549/physiolres.931234

\section{FUNDING}

Supported by a Methusalem grant from KU Leuven to JT.

Bilski, J., Konturek, P. C., Konturek, S. J., Cieszkowski, M., and Czarnobilski, K. (1994). Role of Endogenous Nitric Oxide in the Control of Gastric Acid Secretion, Blood Flow and Gastrin Release in Conscious Dogs. Regul. Peptides 53 (3), 175-184. doi:10.1016/0167-0115(94)90166-x

Bin-Nun, A., and Schreiber, M. D. (2008). Role of iNO in the Modulation of Pulmonary Vascular Resistance. J. Perinatol 28 (Suppl. 3), S84-S92. doi:10.1038/jp.2008.161

Blachier, F., Beaumont, M., and Kim, E. (2019). Cysteine-derived Hydrogen Sulfide and Gut Health. Curr. Opin. Clin. Nutr. Metab. Care 22 (1), 68-75. doi:10.1097/ mco.0000000000000526

Bloom, S. R., Mortimer, C. H., Thorner, M. O., Besser, G. M., Hall, R., Gomez-Pan, A., et al. (1974). Inhibition of Gastrin and Gastric-Acid Secretion by GrowthHormone Release-Inhibiting Hormone. The Lancet 304 (7889), 1106-1109. doi:10.1016/s0140-6736(74)90869-1

Boismenu, R., Rusche, J., and Goulet, M. (2004). Use of Secretin and Secretin Analogs to Treat Affective Disorders. inventors; Repligen Corp, assignee. United Sates: Fish \& Richardson PC

Bormans, V., Peeters, T. L., Janssens, J., Pearce, D., Vandeweerd, M., and Vantrappen, G. (1987). In Man, Only Activity Fronts that Originate in the Stomach Correlate with Motilin Peaks. Scand. J. Gastroenterol. 22 (7), 781-784 doi:10.3109/00365528708991914

Boulant, J., Fioramonti, J., Dapoigny, M., Bommelaer, G., and Bueno, L. (1994). Cholecystokinin and Nitric Oxide in Transient Lower Esophageal Sphincter Relaxation to Gastric Distention in Dogs. Gastroenterology 107 (4), 1059-1066. doi:10.1016/0016-5085(94)90230-5

Bouros, D., Tzouvelekis, A., Anevlavis, S., Doris, M., Tryfon, S., Froudarakis, M., et al. (2006). Smoking Acutely Increases Plasma Ghrelin Concentrations. Clin. Chem. 52 (4), 777-778. doi:10.1373/clinchem.2005.065243

Bradwejn, J., and Koszycki, D. (2001). Cholecystokinin and Panic Disorder: Past and Future Clinical Research Strategies. Scli 61, 19-27. doi:10.1080/ 713783681

Bremholm, L., Hornum, M., Henriksen, B. M., Larsen, S., and Holst, J. J. (2009). Glucagon-like Peptide-2 Increases Mesenteric Blood Flow in Humans. Scand. J. Gastroenterol. 44 (3), 314-319. doi:10.1080/00365520802538195

Brzozowski, T., Konturek, P. C., Konturek, S. J., Pajdo, R., Drozdowicz, D., Kwiecien, S., et al. (1999). Acceleration of Ulcer Healing by Cholecystokinin (CCK): Role of CCK-A Receptors, Somatostatin, Nitric Oxide and Sensory Nerves. Regul. Pept. 82 (1-3), 19-33. doi:10.1016/s0167-0115(99)00029-4

Brzozowski, T., Konturek, S., Drozdowicz, D., Dembiński, A., and Stachura, J. (1995). Healing of Chronic Gastric Ulcerations by L-Arginine. Digestion 56 (6) 463-471. doi:10.1159/000201277

Burgaud, J.-L., Ongini, E., and Soldato, P. (2002). Nitric Oxide-Releasing Drugs. Ann. N. Y Acad. Sci. 962, 360-371. doi:10.1111/j.1749-6632.2002.tb04080.x

Cameron, A. J., Phillips, S. F., and Summerskill, W. H. J. (1970). Comparison of Effects of Gastrin, Cholecystokininpancreozymin, Secretin, and Glucagon on Human Stomach Muscle In Vitro. Gastroenterology 59 (4), 539-545. doi:10.1016/s0016-5085(19)33707-2

Camilleri, M. (2014). Physiological Underpinnings of Irritable Bowel Syndrome: Neurohormonal Mechanisms. J. Physiol. 592 (14), 2967-2980. doi:10.1113/ jphysiol.2014.270892

Carbone, F., Verschueren, S., Rotondo, A., and Tack, J. (2019). Duodenal Nutrient Exposure Contributes to Enhancing Gastric Accommodation. Neurogastroenterol Motil. 31 (11), e13697. doi:10.1111/nmo.13697

Castell, D. O. (1978). Gastrin and Lower Esophageal Sphincter Tone. Arch. Intern. Med. 138 (2), 196. doi:10.1001/archinte.1978.03630260010005

Chai, W., Dong, Z., Wang, N., Wang, W., Tao, L., Cao, W., et al. (2012). Glucagonlike Peptide 1 Recruits Microvasculature and Increases Glucose Use in Muscle via a Nitric Oxide-dependent Mechanism. Diabetes 61 (4), 888-896. doi:10.2337/db11-1073

Chan, M. V., and Wallace, J. L. (2013). Hydrogen Sulfide-Based Therapeutics and Gastrointestinal Diseases: Translating Physiology to Treatments. Am. J. Physiology-Gastrointestinal Liver Physiol. 305 (7), G467-G473. doi:10.1152/ajpgi.00169.2013 
Chandra, R., and Liddle, R. A. (2007). Cholecystokinin. Curr. Opin. Endocrinol. Diabetes Obes. 14 (1), 63-67. doi:10.1097/med.0b013e3280122850

Chen, C., Wu, D., and Clarke, I. J. (1996). Signal Transduction Systems Employed by Synthetic GH-Releasing Peptides in Somatotrophs. J. Endocrinol. 148 (3), 381-386. doi:10.1677/joe.0.1480381

Chen, X., Chen, Q., Wang, L., and Li, G. (2013). Ghrelin Induces Cell Migration through GHSRla-Mediated PI3K/Akt/eNOS/NO Signaling Pathway in Endothelial Progenitor Cells. Metabolism 62 (5), 743-752. doi:10.1016/ j.metabol.2012.09.014

Chen, Y., Lui, V. C. H., Sham, M. H., and Tam, P. K. H. (2002). Distribution of Carbon Monoxide-Producing Neurons in Human colon and in Hirschsprung's Disease Patients. Hum. Pathol. 33 (10), 1030-1036. doi:10.1053/hupa.2002.128251

Chey, W. Y., and Chang, T.-m. (2001). Neural Hormonal Regulation of Exocrine Pancreatic Secretion. Pancreatology 1 (4), 320-335. doi:10.1159/000055831

Chey, W. Y., and Chang, T.-M. (2014). Secretin: Historical Perspective and Current Status. Pancreas 43 (2), 162-182. doi:10.1097/01.mpa.0000437325.29728.d6

Chey, W. Y., and Chang, T.-M. (2003). Secretin, 100 Years Later. J. Gastroenterol. 38 (11), 1025-1035. doi:10.1007/s00535-003-1235-3

Cheyuo, C., Wu, R., Zhou, M., Jacob, A., Coppa, G., and Wang, P. (2011). Ghrelin Suppresses Inflammation and Neuronal Nitric Oxide Synthase in Focal Cerebral Ischemia via the Vagus Nerve. Shock 35 (3), 258-265. doi:10.1097/ shk.0b013e3181f48a37

Chou, C. C., Hsieh, C. P., and Dabney, J. M. (1977). Comparison of Vascular Effects of Gastrointestinal Hormones on Various Organs. Am. J. Physiology-Heart Circulatory Physiol. 232 (2), H103-H109. doi:10.1152/ajpheart.1977.232.2.h103

Chu, S., Tanaka, S., Kaunitz, J. D., and Montrose, M. H. (1999). Dynamic Regulation of Gastric Surface pH by Luminal pH. J. Clin. Invest. 103 (5), 605-612. doi:10.1172/jci5217

Cinci, L., Faussone-Pellegrini, M. S., Rotondo, A., Mulè, F., and Vannucchi, M. G. (2011). GLP-2 Receptor Expression in Excitatory and Inhibitory Enteric Neurons and its Role in Mouse Duodenum Contractility. Neurogastroenterol Motil. 23 (9), e383-e392. doi:10.1111/j.1365-2982.2011.01750.x

Cipriani, S., and Mencarelli, A. (2011). Hydrogen Sulfide in Gastrointestinal and Liver Physiopathology. Iadt 10 (2), 92-102. doi:10.2174/187152811794776231

Coëffier, M., Le Pessot, F., Leplingard, A., Marion, R., Lerebours, E., Ducrotté, P., et al. (2002). Acute Enteral Glutamine Infusion Enhances Heme Oxygenase-1 Expression in Human Duodenal Mucosa. J. Nutr. 132 (9), 2570-2573. doi:10.1093/jn/132.9.2570

Collden, G., Tschop, M. H., and Muller, T. D. (2017). Therapeutic Potential of Targeting the Ghrelin Pathway. Int. J. Mol. Sci. 18 (4), 798. doi:10.3390/ ijms 18040798

Collins, S. M., Lewis, T. D., Fox, J.-A. E. T., Track, N. S., Meghji, M. M., and Daniel, E. E. (1981). Changes in Plasma Motilin Concentration in Response to Manipulation of Intragastric and Intraduodenal Contents in Man. Can. J. Physiol. Pharmacol. 59 (2), 188-194. doi:10.1139/y81-031

Corinaldesi, C., Di Luigi, L., Lenzi, A., and Crescioli, C. (2016). Phosphodiesterase Type 5 Inhibitors: Back and Forward from Cardiac Indications. J. Endocrinol. Invest. 39 (2), 143-151. doi:10.1007/s40618-015-0340-5

Crajoinas, R. O., Oricchio, F. T., Pessoa, T. D., Pacheco, B. P. M., Lessa, L. M. A., Malnic, G., et al. (2011). Mechanisms Mediating the Diuretic and Natriuretic Actions of the Incretin Hormone Glucagon-like Peptide-1. Am. J. PhysiologyRenal Physiol. 301 (2), F355-F363. doi:10.1152/ajprenal.00729.2010

Crawley, J. N., and Corwin, R. L. (1994). Biological Actions of Cholecystokinin. Peptides 15 (4), 731-755. doi:10.1016/0196-9781(94)90104-x

Cummings, D. E., Purnell, J. Q., Frayo, R. S., Schmidova, K., Wisse, B. E., and Weigle, D. S. (2001). A Preprandial Rise in Plasma Ghrelin Levels Suggests a Role in Meal Initiation in Humans. Diabetes 50 (8), 1714-1719. doi:10.2337/ diabetes.50.8.1714

Cuomo, R., Vandaele, P., Coulie, B., Peeters, T., Depoortere, I., Janssens, J., et al. (2006). Influence of Motilin on Gastric Fundus Tone and on Meal-Induced Satiety in Man: Role of Cholinergic Pathways. Am. J. Gastroenterol. 101 (4), 804-811. doi:10.1111/j.1572-0241.2005.00339.x

Currie, P. J., John, C. S., Nicholson, M. L., Chapman, C. D., and Loera, K. E. (2010). Hypothalamic Paraventricular 5-hydroxytryptamine Inhibits the Effects of Ghrelin on Eating and Energy Substrate Utilization. Pharmacol. Biochem. Behav. 97 (1), 152-155. doi:10.1016/j.pbb.2010.05.027

Dai, Y., Mehta, J. L., and Chen, M. (2013). Glucagon-like Peptide-1 Receptor Agonist Liraglutide Inhibits Endothelin-1 in Endothelial Cell by Repressing
Nuclear Factor-Kappa B Activation. Cardiovasc. Drugs Ther. 27 (5), 371-380. doi:10.1007/s10557-013-6463-z

Dass, N. B., Munonyara, M., Bassil, A. K., Hervieu, G. J., Osbourne, S., Corcoran, S., et al. (2003). Growth Hormone Secretagogue Receptors in Rat and Human Gastrointestinal Tract and the Effects of Ghrelin. Neuroscience 120 (2), 443-453. doi:10.1016/s0306-4522(03)00327-0

Date, Y., Kojima, M., Hosoda, H., Sawaguchi, A., Mondal, M. S., Suganuma, T., et al. (2000). Ghrelin, a Novel Growth Hormone-Releasing Acylated Peptide, Is Synthesized in a Distinct Endocrine Cell Type in the Gastrointestinal Tracts of Rats and Humans1. Endocrinology 141 (11), 4255-4261. doi:10.1210/ endo.141.11.7757

Date, Y., Murakami, N., Toshinai, K., Matsukura, S., Niijima, A., Matsuo, H., et al. (2002). The Role of the Gastric Afferent Vagal Nerve in Ghrelin-Induced Feeding and Growth Hormone Secretion in Rats. Gastroenterology 123 (4), 1120-1128. doi:10.1053/gast.2002.35954

Deloose, E., Janssen, P., Depoortere, I., and Tack, J. (2012). The Migrating Motor Complex: Control Mechanisms and its Role in Health and Disease. Nat. Rev. Gastroenterol. Hepatol. 9 (5), 271-285. doi:10.1038/nrgastro.2012.57

Deloose, E., Verbeure, W., Depoortere, I., and Tack, J. (2019). Motilin: from Gastric Motility Stimulation to Hunger Signalling. Nat. Rev. Endocrinol. 15 (4), 238-250. doi:10.1038/s41574-019-0155-0

Demarchi, B., Vos, R., Deprez, P., Janssens, J., and Tack, J. (2004). Influence of a Lipase Inhibitor on Gastric Sensitivity and Accommodation to an Orally Ingested Meal. Aliment. Pharmacol. Ther. 19 (12), 1261-1268. doi:10.1111/ j.1365-2036.2004.02003.x

Dezaki, K., Hosoda, H., Kakei, M., Hashiguchi, S., Watanabe, M., Kangawa, K., et al. (2004). Endogenous Ghrelin in Pancreatic Islets Restricts Insulin Release by Attenuating Ca2 + Signaling in -Cells: Implication in the Glycemic Control in Rodents. Diabetes 53 (12), 3142-3151. doi:10.2337/diabetes.53.12.3142

Ding, Y., McCoubrey Jr, W. K., Jr., and Maines, M. D. (1999). Interaction of Heme Oxygenase-2 with Nitric Oxide Donors. Is the Oxygenase an Intracellular 'sink' for NO?. Eur. J. Biochem. 264 (3), 854-861. doi:10.1046/j.14321327.1999.00677.x

Dobutovic, B., Sudar, E., Tepavcevic, S., Djordjevic, J., Djordjevic, A., Radojcic, M., et al. (2014). Experimental Research Effects of Ghrelin on Protein Expression of Antioxidative Enzymes and iNOS in the Rat Liver. aoms 4 (4), 806-816. doi:10.5114/aoms.2014.44872

Doi, R., Hosotani, R., Inoue, K., Kogire, M., Sumi, S., Fujii, N., et al. (1990). Effect of Synthetic Human Cholecystokinin-33 on Pancreatic Blood Flow in Dogs. Pancreas 5 (5), 615-620. doi:10.1097/00006676-199009000-00019

Domschke, W., Lux, G., Mitznegg, P., Rösch, W., and Domschke, S. (1976). Endogenous Motilin and Lower Esophageal Sphincter Pressure in Man: Clue to an Association. Acta Hepatogastroenterol (Stuttg) 23 (4), 274-275.

Dong, Z., Chai, W., Wang, W., Zhao, L., Fu, Z., Cao, W., et al. (2013). Protein Kinase A Mediates Glucagon-like Peptide 1-induced Nitric Oxide Production and Muscle Microvascular Recruitment. Am. J. Physiology-Endocrinology Metab. 304 (2), E222-E228. doi:10.1152/ajpendo.00473.2012

Drucker, D. J., and Yusta, B. (2014). Physiology and Pharmacology of the Enteroendocrine Hormone Glucagon-like Peptide-2. Annu. Rev. Physiol. 76, 561-583. doi:10.1146/annurev-physiol-021113-170317

Dubé, P. E., and Brubaker, P. L. (2007). Frontiers in Glucagon-like Peptide-2: Multiple Actions, Multiple Mediators. Am. J. Physiology-Endocrinology Metab. 293 (2), E460-E465. doi:10.1152/ajpendo.00149.2007

Dudzinski, D. M., Igarashi, J., Greif, D., and Michel, T. (2006). The Regulation and Pharmacology of Endothelial Nitric Oxide Synthase. Annu. Rev. Pharmacol. Toxicol. 46, 235-276. doi:10.1146/annurev.pharmtox.44.101802.121844

Dufresne, M., Seva, C., and Fourmy, D. (2006). Cholecystokinin and Gastrin Receptors. Physiol. Rev. 86 (3), 805-847. doi:10.1152/physrev.00014.2005

Eissele, R., Göke, R., Willemer, S., Harthus, H.-P., Vermeer, H., Arnold, R., et al. (1992). Glucagon-like Peptide-1 Cells in the Gastrointestinal Tract and Pancreas of Rat, Pig and Man. Eur. J. Clin. Invest. 22 (4), 283-291. doi:10.1111/j.1365-2362.1992.tb01464.x

Engel, R. R., Matsen, J. M., Chapman, S. S., and Schwartz, S. (1972). Carbon Monoxide Production from Heme Compounds by Bacteria. J. Bacteriol. 112 (3), 1310-1315. doi:10.1128/jb.112.3.1310-1315.1972

Erdogdu, O., Nathanson, D., Sjoholm, A., Nystrom, T., and Zhang, Q. (2010). Exendin-4 Stimulates Proliferation of Human Coronary Artery Endothelial Cells through eNOS-, PKA- and PI3K/Akt-dependent Pathways and Requires 
GLP-1 Receptor. Mol. Cell Endocrinol 325 (1-2), 26-35. doi:10.1016/ j.mce.2010.04.022

Ericson, A., Nur, E. M., Petersson, F., and Kechagias, S. (2009). The Effects of Capsaicin on Gastrin Secretion in Isolated Human Antral Glands: before and after Ingestion of Red Chilli. Dig. Dis. Sci. 54 (3), 491-498. doi:10.1007/s10620008-0400-1

Esplugues, J. V., Barrachina, M. D., Beltran, B., Calatayud, S., Whittle, B. J. R., and Moncada, S. (1996). Inhibition of Gastric Acid Secretion by Stress: a Protective Reflex Mediated by Cerebral Nitric Oxide. Proc. Natl. Acad. Sci. 93 (25), 14839-14844. doi:10.1073/pnas.93.25.14839

Evangelista, S., Maggi, C. A., and Meli, A. (1987). Influence of PeripherallyAdministered Peptides on Ethanol-Induced Gastric Ulcers in the Rat. Gen. Pharmacol. Vasc. Syst. 18 (6), 647-649. doi:10.1016/0306-3623(87)90039-5

Evangelista, S., and Maggi, C. A. (1991). Protection Induced by Cholecystokinin-8 (CCK-8) in Ethanol-Induced Gastric Lesions Is Mediated via Vagal CapsaicinSensitive Fibres and CCKA Receptors. Br. J. Pharmacol. 102 (1), 119-122. doi:10.1111/j.1476-5381.1991.tb12142.x

Ewing, J. F., and Maines, M. D. (1992). In Situ hybridization and Immunohistochemical Localization of Heme Oxygenase-2 mRNA and Protein in normal Rat Brain: Differential Distribution of Isozyme 1 and 2. Mol. Cell Neurosci. 3 (6), 559-570. doi:10.1016/1044-7431(92)90068-d

Ferraro, G., Sardo, P., Di Giovanni, G., Di Maio, R., and La Grutta, V. (2003). CCKnitric Oxide Interaction in Rat Cortex, Striatum and Pallidum. Comp. Biochem. Physiol. C: Toxicol. Pharmacol. 135 (4), 425-433. doi:10.1016/s1532-0456(03) 00144-3

Fiorucci, S., Antonelli, E., Distrutti, E., Rizzo, G., Mencarelli, A., Orlandi, S., et al. (2005). Inhibition of Hydrogen Sulfide Generation Contributes to Gastric Injury Caused by Anti-inflammatory Nonsteroidal Drugs. Gastroenterology 129 (4), 1210-1224. doi:10.1053/j.gastro.2005.07.060

Fiorucci, S., and McArthur, K. E. (1990). Gastrin-releasing Peptide Directly Releases Pepsinogen from guinea Pig Chief Cells. Am. J. PhysiologyGastrointestinal Liver Physiol. 259 (5 Pt 1), G760-G766. doi:10.1152/ ajpgi.1990.259.5.g760

Fiorucci, S., Santucci, L., Gresele, P., Faccino, R. M., Del Soldato, P., and Morelli, A. (2003). Gastrointestinal Safety of NO-Aspirin (NCX-4016) in Healthy Human Volunteers: a Proof of Concept Endoscopic Study. Gastroenterology 124 (3), 600-607. doi:10.1053/gast.2003.50096

Fisher, R. S., Lipshutz, W., and Cohen, S. (1973). The Hormonal Regulation of Pyloric Sphincter Function. J. Clin. Invest. 52 (5), 1289-1296. doi:10.1172/ jci107297

Foresti, R., Bani-Hani, M. G., and Motterlini, R. (2008). Use of Carbon Monoxide as a Therapeutic Agent: Promises and Challenges. Intensive Care Med. 34 (4), 649-658. doi:10.1007/s00134-008-1011-1

Fornai, M., Colucci, R., Antonioli, L., Crema, F., Buccianti, P., Chiarugi, M., et al. (2007). Cholecystokinin CCK2 Receptors Mediate the Peptide's Inhibitory Actions on the Contractile Activity of Human Distal colon via the Nitric Oxide Pathway. Br. J. Pharmacol. 151 (8), 1246-1253. doi:10.1038/ sj.bjp.0707339

Förstermann, U., and Kleinert, H. (1995). Nitric Oxide Synthase: Expression and Expressional Control of the Three Isoforms. Naunyn Schmiedebergs Arch. Pharmacol. 352 (4), 351-364. doi:10.1007/BF00172772

Foster-Schubert, K. E., Overduin, J., Prudom, C. E., Liu, J., Callahan, H. S., Gaylinn, B. D., et al. (2008). Acyl and Total Ghrelin Are Suppressed Strongly by Ingested Proteins, Weakly by Lipids, and Biphasically by Carbohydrates. J. Clin. Endocrinol. Metab. 93 (5), 1971-1979. doi:10.1210/jc.2007-2289

French, S. J., Murray, B., Rumsey, R. D. E., Fadzlin, R., and Read, N. W. (1995). Adaptation to High-Fat Diets: Effects on Eating Behaviour and Plasma Cholecystokinin. Br. J. Nutr. 73 (2), 179-189. doi:10.1079/bjn19950022

Gallego, d., clavé, p., Donovan, j., Rahmati, r., Grundy, d., jiménez, m., et al. (2008). The Gaseous Mediator, Hydrogen Sulphide, Inhibitsin Vitromotor Patterns in the Human, Rat and Mouse colon and Jejunum. Neurogastroenterol Motil. 20 (12), 1306-1316. doi:10.1111/j.1365-2982.2008.01201.x

Garcia, J. M., Friend, J., and Allen, S. (2013). Therapeutic Potential of Anamorelin, a Novel, Oral Ghrelin Mimetic, in Patients with Cancer-Related Cachexia: a Multicenter, Randomized, Double-Blind, Crossover, Pilot Study. Support Care Cancer. 21 (1), 129-137. doi:10.1007/s00520-012-1500-1

García-Zaragozá, E., Barrachina, M. D., Moreno, L., and Esplugues, J. V. (2000). Role of central Glutamate Receptors, Nitric Oxide and Soluble Guanylyl Cyclase in the Inhibition by Endotoxin of Rat Gastric Acid Secretion. Br. J. Pharmacol. 130 (6), 1283-1288. doi:10.1038/sj.bjp.0703436

Garin, M. C., Burns, C. M., Kaul, S., and Cappola, A. R. (2013). The Human Experience with Ghrelin Administration. J. Clin. Endocrinol. Metab. 98 (5), 1826-1837. doi:10.1210/jc.2012-4247

Gaskin, F. S., Farr, S. A., Banks, W. A., Kumar, V. B., and Morley, J. E. (2003). Ghrelin-induced Feeding Is Dependent on Nitric Oxide. Peptides 24 (6), 913-918. doi:10.1016/s0196-9781(03)00160-8

Geenen, J. E., Hogan, W. J., Dodds, W. J., Stewart, E. T., and Arndorfer, R. C. (1980). Intraluminal Pressure Recording from the Human Sphincter of Oddi. Gastroenterology 78 (2), 317-324. doi:10.1016/0016-5085(80)90582-x

Geraedts, M. C. P., Troost, F. J., Tinnemans, R., Söderholm, J. D., Brummer, R. J., and Saris, W. H. M. (2010). Release of Satiety Hormones in Response to Specific Dietary Proteins Is Different between Human and Murine Small Intestinal Mucosa. Ann. Nutr. Metab. 56 (4), 308-313. doi:10.1159/000312664

Gnanapavan, S., Kola, B., Bustin, S. A., Morris, D. G., McGee, P., Fairclough, P., et al. (2002). The Tissue Distribution of the mRNA of Ghrelin and Subtypes of its Receptor, GHS-R, in Humans. J. Clin. Endocrinol. Metab. 87 (6), 2988-2991. doi:10.1210/jcem.87.6.8739

Göke, R., Larsen, P. J., Mikkelsen, J. D., and Sheikh, S. P. (1995). Distribution of GLP-1 Binding Sites in the Rat Brain: Evidence that Exendin-4 Is a Ligand of Brain GLP-1 Binding Sites. Eur. J. Neurosci. 7 (11), 2294-2300. doi:10.1111/ j.1460-9568.1995.tb00650.x

Green, B. D., Hand, K. V., Dougan, J. E., McDonnell, B. M., Cassidy, R. S., and Grieve, D. J. (2008). GLP-1 and Related Peptides Cause Concentrationdependent Relaxation of Rat Aorta through a Pathway Involving KATP and cAMP. Arch. Biochem. Biophys. 478 (2), 136-142. doi:10.1016/ j.abb.2008.08.001

Green, G. M., and Lyman, R. L. (1972). Feedback Regulation of Pancreatic Enzyme Secretion as a Mechanism for Trypsin Inhibitor-Induced Hypersecretion in Rats. Exp. Biol. Med. 140 (1), 6-12. doi:10.3181/ 00379727-140-36384

Grossini, E., Caimmi, P., Molinari, C., Uberti, F., Mary, D., and Vacca, G. (1985). Intracoronary Gastrin 17 Increases Cardiac Perfusion and Function through Autonomic Nervous System, CCK Receptors, and Nitric Oxide in Anesthetized Pigs. J. Appl. Physiol. (1985) 110 (1), 95-108. doi:10.1152/japplphysiol.00625.2010

Grossini, E., Caimmi, P., Molinari, C., Uberti, F., Mary, D., and Vacca, G. (2012). CCK Receptors-Related Signaling Involved in Nitric Oxide Production Caused by Gastrin 17 in Porcine Coronary Endothelial Cells. Mol. Cell Endocrinol. 350 (1), 20-30. doi:10.1016/j.mce.2011.11.018

Grossini, E., Molinari, C., Uberti, F., Mary, D. A. S. G., Vacca, G., and Caimmi, P. P. (2011). Intracoronary Melatonin Increases Coronary Blood Flow and Cardiac Function through $\beta$-adrenoreceptors, MT1/MT2 Receptors, and Nitric Oxide in Anesthetized Pigs. J. Pineal Res. 51 (2), 246-257. doi:10.1111/j.1600079x.2011.00886.x

Guan, X., Karpen, H. E., Stephens, J., Bukowski, J. T., Niu, S., Zhang, G., et al. (2006). GLP-2 Receptor Localizes to Enteric Neurons and Endocrine Cells Expressing Vasoactive Peptides and Mediates Increased Blood Flow. Gastroenterology 130 (1), 150-164. doi:10.1053/j.gastro.2005.11.005

Guan, X., Stoll, B., Lu, X., Tappenden, K. A., Holst, J. J., Hartmann, B., et al. (2003). GLP2-mediated Up-Regulation of Intestinal Blood Flow and Glucose Uptake Is Nitric Oxide-dependent in TPN-Fed Piglets 1 1This Work Is a Publication of the USDA/ ARS Children's Nutrition Research Center, Department of Pediatrics, Baylor College of Medicine and Texas Children's Hospital, Houston, Texas. Gastroenterology 125 (1), 136-147. doi:10.1016/s0016-5085(03)00667-x

Guan, Y., Tang, M., Jiang, Z., and Peeters, T. L. (2003). Excitatory Effects of Motilin in the hippocampus on Gastric Motility in Rats. Brain Res. 984 (1-2), 33-41. doi:10.1016/s0006-8993(03)03016-6

Gunnes, P., and Rasmussen, K. (1986). Haemodynamic Effects of Pharmacological Doses of Secretin in Patients with Impaired Left Ventricular Function. Eur. Heart J. 7 (2), 146-149. doi:10.1093/oxfordjournals.eurheartj.a062037

Gunnes, P., Waldum, H. L., Rasmussen, K., Østensen, H., and Burhol, P. G. (1983). Cardiovascular Effects of Secretin Infusion in Man. Scli 43 (7), 637-642. doi: $10.3109 / 00365518309168843$

Gutzwiller, J.-P., Tschopp, S., Bock, A., Zehnder, C. E., Huber, A. R., Kreyenbuehl, M., et al. (2004). Glucagon-like Peptide 1 Induces Natriuresis in Healthy Subjects and in Insulin-Resistant Obese Men. J. Clin. Endocrinol. Metab. 89 (6), 3055-3061. doi:10.1210/jc.2003-031403 
Guzik, T. J., and Harrison, D. G. (2006). Vascular NADPH Oxidases as Drug Targets for Novel Antioxidant Strategies. Drug Discov. Today 11 (11-12), 524-533. doi:10.1016/j.drudis.2006.04.003

Hacki, W. H. (1980). Secretin. Clin. Gastroenterol. 9 (3), 609-632. doi:10.1016/ s0300-5089(21)00474-0

Hakim, T. S., Sugimori, K., Camporesi, E. M., and Anderson, G. (1996). Half-life of Nitric Oxide in Aqueous Solutions with and without Haemoglobin. Physiol. Meas. 17 (4), 267-277. doi:10.1088/0967-3334/17/4/004

Halim, M. A., Gillberg, L., Boghus, S., Sundbom, M., Karlbom, U., Webb, D.-L., et al. (2015). Nitric Oxide Regulation of Migrating Motor Complex: Randomized Trial of NG-Monomethyl-L-Arginine Effects in Relation to Muscarinic and Serotonergic Receptor Blockade. Acta Physiol. 215 (2), 105-118. doi:10.1111/apha.12554

Han, C., Zhao, Q., and Lu, B. (2013). The Role of Nitric Oxide Signaling in Food Intake; Insights from the Inner Mitochondrial Membrane Peptidase 2 Mutant Mice. Redox Biol. 1, 498-507. doi:10.1016/j.redox.2013.10.003

Han, L., Yu, Y., Sun, X., and Wang, B. (2012). Exendin-4 Directly Improves Endothelial Dysfunction in Isolated Aortas from Obese Rats through the cAMP or AMPK-eNOS Pathways. Diabetes Res. Clin. Pract. 97 (3), 453-460. doi:10.1016/j.diabres.2012.04.001

He, J., Irwin, D. M., Chen, R., and Zhang, Y.-P. (2010). Stepwise Loss of Motilin and its Specific Receptor Genes in Rodents. J. Mol. Endocrinol. 44 (1), 37-44. doi:10.1677/jme-09-0095

Hedayati, N., Annambhotla, S., Jiang, J., Wang, X., Chai, H., Lin, P. H., et al. (2009). Growth Hormone-Releasing Peptide Ghrelin Inhibits Homocysteine-Induced Endothelial Dysfunction in Porcine Coronary Arteries and Human Endothelial Cells. J. Vasc. Surg. 49 (1), 199-207. doi:10.1016/j.jvs.2008.08.065

Heinemann, A., Jociê, M., Holzer-Petsche, U., Pethö, G., Peskar, B. M., Horwell, D. C., et al. (1995). Mediation by CCKB Receptors of the CCK-Evoked Hyperaemia in Rat Gastric Mucosa. Br. J. Pharmacol. 116 (4), 2274-2278. doi:10.1111/j.1476-5381.1995.tb15064.x

Heinemann, A., Jocic, M., Peskar, B. M., and Holzer, P. (1996). CCK-evoked Hyperemia in Rat Gastric Mucosa Involves Neural Mechanisms and Nitric Oxide. Am. J. Physiology-Gastrointestinal Liver Physiol. 270 (2 Pt 1), G253-G258. doi:10.1152/ajpgi.1996.270.2.g253

Hermann, A., Sitdikova, G. F., and Weiger, T. M. (2012). Gasotransmitters Physiology and Pathophysiology. New York: Springer.

Holst, J. J. (2007). The Physiology of Glucagon-like Peptide 1. Physiol. Rev. 87 (4), 1409-1439. doi:10.1152/physrev.00034.2006

Hornum, I., Fahrenkrug, J., and Rehfeld, J. F. (1976). Gastrointestinal Effect of Calcitonin: Inhibition of Gastrin Secretion. Calcif Tissue Res. 21 (Suppl. 1), 299-303. doi:10.1007/978-3-662-29272-3_45

Hu, Y., Yang, M., Ma, N., Shinohara, H., and Semba, R. (1998). Contribution of Carbon Monoxide-Producing Cells in the Gastric Mucosa of Rat and Monkey. Histochem. Cell Biol 109 (4), 369-373. doi:10.1007/s004180050237

Huang, X.-L., Ling, Y. L., Ling, Y. Q., Zhou, J. L., Liu, Y., and Wang, Q. H. (2004). Heme Oxygenase-1 in Cholecystokinin-Octapeptipe Attenuated Injury of Pulmonary Artery Smooth Muscle Cells Induced by Lipopolysaccharide and its Signal Transduction Mechanism. Wjg 10 (12), 1789-1794. doi:10.3748/wjg.v10.i12.1789

Hughes, C. F., Ward, M., Tracey, F., Hoey, L., Molloy, A. M., Pentieva, K., et al. (2017). B-vitamin Intake and Biomarker Status in Relation to Cognitive Decline in Healthy Older Adults in a 4-Year Follow-Up Study. Nutrients 9 (1), 53. doi: $10.3390 /$ nu 9010053

Iantorno, M., Chen, H., Kim, J.-a., Tesauro, M., Lauro, D., Cardillo, C., et al. (2007). Ghrelin Has Novel Vascular Actions that Mimic PI 3-kinase-dependent Actions of Insulin to Stimulate Production of NO from Endothelial Cells. Am. J. PhysiologyEndocrinology Metab. 292 (3), E756-E764. doi:10.1152/ajpendo.00570.2006

Ismailova, A., Kuter, D., Bohle, D. S., and Butler, I. S. (2018). An Overview of the Potential Therapeutic Applications of CO-Releasing Molecules. Bioinorg Chem. Appl. 2018, 8547364. doi:10.1155/2018/8547364

Itoh, Z., Takeuchi, S., Aizawa, I., and Honda, R. (1975). The Negative Feedback Mechanism of Gastric Acid Secretion: Significance of Acid in the Gastric Juice in Man and Dog. Surgery 77 (5), 648-660.

Itoh, Z. (1997). Motilin and Clinical Application. Peptides 18 (4), 593-608. doi:10.1016/s0196-9781(96)00333-6

Iwase, M., Uchizono, Y., Nakamura, U., Nohara, S., and Iida, M. (2003). Effect of Exogenous Cholecystokinin on Islet Blood Flow in Anesthetized Rats. Regul. Pept. 116 (1-3), 87-93. doi:10.1016/j.regpep.2003.07.002
Janssen, P., Rotondo, A., Mulé, F., and Tack, J. (2013). Review Article: a Comparison of Glucagon-like Peptides 1 and 2. Aliment. Pharmacol. Ther. 37 (1), 18-36. doi:10.1111/apt.12092

Jenssen, T. G., Burhol, P. G., Jorde, R., Florholmen, J., and Lygren, I. (1984). Radioimmunoassayable Plasma Motilin in Man. Scand. J. Gastroenterol. 19 (6), 717-723. doi:10.1080/00365521.1984.12005799

Jenssen, T. G., Haukland, H. H., Florholmen, J., Jorde, R., and Burhol, P. G. (1986). Evidence of Somatostatin as a Humoral Modulator of Motilin Release in Man: A Study of Plasma Motilin and Somatostatin during Intravenous Infusion of Somatostatin, Secretin, Cholecystokinin, and Gastric Inhibitory Polypeptide. Scand. J. Gastroenterol. 21 (3), 273-280. doi:10.3109/00365528609003076

Jimenez-Feltstrom, J., Lundquist, I., and Salehi, A. (2005). Glucose Stimulates the Expression and Activities of Nitric Oxide Synthases in Incubated Rat Islets: an Effect Counteracted by GLP-1 through the Cyclic AMP/PKA Pathway. Cell Tissue Res 319 (2), 221-230. doi:10.1007/s00441-004-1013-4

Jyotheeswaran, S., Li, P., Chang, T.-M., and Chey, W. Y. (2000). Endogenous Nitric Oxide Mediates Pancreatic Exocrine Secretion Stimulated by Secretin and Cholecystokinin in Rats. Pancreas 20 (4), 401-407. doi:10.1097/00006676200005000-00011

Kamerling, I. M. C., Burggraaf, J., van Haarst, A. D., Oppenhuizen-Duinker, M. F., Schoemaker, H. C., Biemond, I., et al. (2003). The Effect of Motilin on the Rectum in Healthy Volunteers. Br. J. Clin. Pharmacol. 55 (6), 538-543. doi:10.1046/j.1365-2125.2003.01812.x

Kastin, A. J., Akerstrom, V., and Pan, W. (2002). Interactions of Glucagon-like Peptide-1 (GLP-1) with the Blood-Brain Barrier. J. Mol. Neurosci. 18 (1-2), 7-14. doi:10.1385/jmn:18:1-2:07

Kim, H. P., Ryter, S. W., and Choi, A. M. K. (2006). CO as a Cellular Signaling Molecule. Annu. Rev. Pharmacol. Toxicol. 46, 411-449. doi:10.1146/ annurev.pharmtox.46.120604.141053

Kimura, H. (2014). Production and Physiological Effects of Hydrogen Sulfide. Antioxid. Redox Signaling 20 (5), 783-793. doi:10.1089/ars.2013.5309

Kimura, K., Nakamura, Y., Hasegawa, H., Tsuji, M., Oguchi, T., Tsuchiya, H., et al. (2016). Pleiotropic Effects of Linagliptin Monotherapy on Levels of Nitric Oxide, Nitric Oxide Synthase, and Superoxide Dismutase in Hemodialysis Patients with Diabetes. Showa Univ. J. Med. Sci. 28 (1), 9-17. doi:10.15369/ sujms. 28.9

Kindt, S., and Tack, J. (2006). Impaired Gastric Accommodation and its Role in Dyspepsia. Gut 55 (12), 1685-1691. doi:10.1136/gut.2005.085365

Kirchgessner, A. L., Liu, M.-T., and Gershon, M. D. (1994). NADPH Diaphorase (Nitric Oxide Synthase)-Containing Nerves in the Enteropancreatic Innervation: Sources, Co-stored Neuropeptides, and Pancreatic Function. J. Comp. Neurol. 342 (1), 115-130. doi:10.1002/cne.903420111

Kitazawa, T., Onodera, C., and Taneike, T. (2002). Potentiation of Motilin-Induced Contraction by Nitric Oxide Synthase Inhibition in the Isolated Chicken Gastrointestinal Tract. Neurogastroenterol Motil. 14 (1), 3-13. doi:10.1046/ j.1365-2982.2002.00298.x

Kojima, M., Hosoda, H., Date, Y., Nakazato, M., Matsuo, H., and Kangawa, K. (1999). Ghrelin Is a Growth-Hormone-Releasing Acylated Peptide from Stomach. Nature 402 (6762), 656-660. doi:10.1038/45230

Kojima, M., and Kangawa, K. (2005). Ghrelin: Structure and Function. Physiol. Rev. 85 (2), 495-522. doi:10.1152/physrev.00012.2004

Konturek, J. W., Hengst, K., Kulesza, E., Gabryelewicz, A., Konturek, S. J., and Domschke, W. (1997). Role of Endogenous Nitric Oxide in the Control of Exocrine and Endocrine Pancreatic Secretion in Humans. Gut 40 (1), 86-91. doi:10.1136/gut.40.1.86

Konturek, P. C., Brzozowski, T., Walter, B., Burnat, G., Hess, T., Hahn, E. G., et al. (2006). Ghrelin-induced Gastroprotection against Ischemia-Reperfusion Injury Involves an Activation of Sensory Afferent Nerves and Hyperemia Mediated by Nitric Oxide. Eur. J. Pharmacol. 536 (1-2), 171-181. doi:10.1016/ j.ejphar.2006.02.032

Konturek, S. J., Brzozowski, T., Pytko-Polonczyk, J., and Drozdowicz, D. (1995). Exogenous and Endogenous Cholecystokinin Protects Gastric Mucosa against the Damage Caused by Ethanol in Rats. Eur. J. Pharmacol. 273 (1-2), 57-62. doi:10.1016/0014-2999(94)00674-v

Konturek, S. J., Bilski, J., Konturek, P. K., Cieszkowski, M., and Pawlik, W. (1993). Role of Endogenous Nitric Oxide in the Control of Canine Pancreatic Secretion and Blood Flow. Gastroenterology 104 (3), 896-902. doi:10.1016/0016-5085(93) 91028-g 
Konturek, S. J., Brzozowski, T., Bielanski, W., and Schally, A. V. (1995). Role of Endogenous Gastrin in Gastroprotection. Eur. J. Pharmacol. 278 (3), 203-212. doi:10.1016/0014-2999(95)00120-a

Konturek, S. J., Brzozowski, T., Pytko-Polonczyk, J., and Drozdowicz, D. (1995). Comparison of Cholecystokinin, Pentagastrin, and Duodenal Oleate in Gastroprotection in Rats. Scand. J. Gastroenterol. 30 (7), 620-630. doi:10.3109/00365529509096303

Kopincová, J., Púzserová, A., and Bernátová, I. (2012). L-NAME in the Cardiovascular System - Nitric Oxide Synthase Activator?. Pharmacol. Rep. 64 (3), 511-520. doi:10.1016/s1734-1140(12)70846-0

Koska, J., Sands, M., Burciu, C., D’Souza, K. M., Raravikar, K., Liu, J., et al. (2015). Exenatide Protects against Glucose- and Lipid-Induced Endothelial Dysfunction: Evidence for Direct Vasodilation Effect of GLP-1 Receptor Agonists in Humans. Diabetes 64 (7), 2624-2635. doi:10.2337/db14-0976

Krasner, N. M., Ido, Y., Ruderman, N. B., and Cacicedo, J. M. (2014). Glucagon-like Peptide-1 (GLP-1) Analog Liraglutide Inhibits Endothelial Cell Inflammation through a Calcium and AMPK Dependent Mechanism. PLoS One 9 (5), e97554. doi:10.1371/journal.pone.0097554

Kurjak, M., Schusdziarra, V., and Allescher, H. D. (1996). Presynaptic Modulation by VIP, Secretin and Isoproterenol of Somatostatin Release from Enriched Enteric Synaptosomes: Role of cAMP. Eur. J. Pharmacol. 314 (1-2), 165-173. doi:10.1016/s0014-2999(96)00516-X

Lange, W., Unger, J., Pitzl, H., and Weindl, A. (1986). Is Motilin a Cerebellar Peptide in the Rat?. Anat. Embryol. 173 (3), 371-376. doi:10.1007/bf00318921

Layer, P., Juul Holst, J., Grandt, D., and Goebell, H. (1995). Ileal Release of Glucagon-like Peptide-1 (GLP-1). Dig. Dis Sci 40 (5), 1074-1082. doi:10.1007/ bf02064202

Li, Y.-F., Xiao, C.-S., and Hui, R.-T. (2009). Calcium Sulfide (CaS), a Donor of Hydrogen Sulfide (H2S): A New Antihypertensive Drug?. Med. Hypotheses 73 (3), 445-447. doi:10.1016/j.mehy.2009.03.030

Lim, G. E., and Brubaker, P. L. (2006). Glucagon-Like Peptide 1 Secretion by the L-Cell: The View from within. Diabetes 55 (Suppl. 2), S70-S77. doi:10.2337/ db06-s020

Lim, G. E., Huang, G. J., Flora, N., LeRoith, D., Rhodes, C. J., and Brubaker, P. L. (2009). Insulin Regulates Glucagon-like Peptide-1 Secretion from the Enteroendocrine L Cell. Endocrinology 150 (2), 580-591. doi:10.1210/ en.2008-0726

Linden, D. R. (2014). Hydrogen Sulfide Signaling in the Gastrointestinal Tract. Antioxid. Redox Signaling 20 (5), 818-830. doi:10.1089/ars.2013.5312

Ling, K., Men, F., Wang, W. C., Zhou, Y. Q., Zhang, H. W., and Ye, D. W. (2018). Carbon Monoxide and its Controlled Release: Therapeutic Application, Detection, and Development of Carbon Monoxide Releasing Molecules (CORMs). J. Med. Chem. 61 (7), 2611-2635. doi:10.1021/ acs.jmedchem.6b01153

Ling, Y. L., Meng, A. H., Zhao, X. Y., Shan, B. E., Zhang, J. L., and Zhang, X. P. (2001). Effect of Cholecystokinin on Cytokines during Endotoxic Shock in Rats. Wjg 7 (5), 667-671. doi:10.3748/wjg.7.667

Liu, B., Liu, X., and Tang, C. (2006). Change of Plasma Ghrelin Level in Acute Pancreatitis. Pancreatology 6 (6), 531-535. doi:10.1159/000096976

Liu, L., Liu, J., and Huang, Y. (2015). Protective Effects of Glucagon-like Peptide 1 on Endothelial Function in Hypertension. J. Cardiovasc. Pharmacol. 65 (5), 399-405. doi:10.1097/fjc.0000000000000176

Liu, M., Dong, L., and Zhu, W. Y. (2005). [Distribution and Role of Motilin Receptor in the Amygdala of Rats]. Di Yi Jun Yi Da Xue Xue Bao 25 (9), 1100-1104. doi:10.1016/S1000-1948(08)60013-1

Lorber, D. (2013). GLP -1 Receptor Agonists: Effects on Cardiovascular Risk Reduction. Cardiovasc. Ther. 31 (4), 238-249. doi:10.1111/1755-5922.12000

Lovick, T. A. (2009). CCK as a Modulator of Cardiovascular Function. J. Chem. Neuroanat. 38 (3), 176-184. doi:10.1016/j.jchemneu.2009.06.007

Lu, Y., Lu, D., and Hu, Y. (2018). Glucagon-like Peptide 2 Decreases Osteoclasts by Stimulating Apoptosis Dependent on Nitric Oxide Synthase. Cell Prolif 51 (4), e12443. doi:10.1111/cpr.12443

Lu, y., and Owyang, c. (2009). Secretin-induced Gastric Relaxation Is Mediated by Vasoactive Intestinal Polypeptide and Prostaglandin Pathways. Neurogastroenterol Motil. $21 \quad$ (7), 754-e47. doi:10.1111/j.13652982.2009.01271.x

Lu, Y., Zhong, F., Wang, X., Li, H., Zhu, Z., Kong, X., et al. (2015). Mechanism of Motilin-Mediated Inhibition on Voltage-dependent Potassium Currents in
Hippocampal Neurons. Neuroscience 284, 374-380. doi:10.1016/ j.neuroscience.2014.08.020

Luiking, Y. C., Peeters, T. L., Stolk, M. F. J., Nieuwenhuijs, V. B., Portincasa, P., Depoortere, I., et al. (1998). Motilin Induces Gall Bladder Emptying and Antral Contractions in the Fasted State in Humans. Gut 42 (6), 830-835. doi:10.1136/ gut.42.6.830

Lund, P. K. (2005). The Discovery of Glucagon-like Peptide 1. Regul. Peptides 128 (2), 93-96. doi:10.1016/j.regpep.2004.09.001

Lundquist, I., Alm, P., Salehi, A., Henningsson, R., Grapengiesser, E., and Hellman, B. (2003). Carbon Monoxide Stimulates Insulin Release and Propagates Ca2+ Signals between Pancreatic $\beta$-cells. Am. J. Physiology-Endocrinology Metab. 285 (5), E1055-E1063. doi:10.1152/ajpendo.00498.2002

Maines, M. D. (1988). Heme Oxygenase: Function, Multiplicity, Regulatory Mechanisms, and Clinical Applications. FASEB j. 2 (10), 2557-2568. doi:10.1096/fasebj.2.10.3290025

Maines, M. D. (1997). The Heme Oxygenase System:A Regulator of Second Messenger Gases. Annu. Rev. Pharmacol. Toxicol. 37, 517-554. doi:10.1146/ annurev.pharmtox.37.1.517

Mancuso, C., Preziosi, P., Grossman, A. B., and Navarra, P. (1997). The Role of Carbon Monoxide in the Regulation of Neuroendocrine Function. Neuroimmunomodulation 4 (5-6), 225-229. doi:10.1159/000097340

Mard, S. A., Askari, H., Neisi, N., and Veisi, A. (2014). Antisecretory Effect of Hydrogen Sulfide on Gastric Acid Secretion and the Involvement of Nitric Oxide. Biomed. Res. Int. 2014, 480921. doi:10.1155/2014/480921

Mard, S. A., Godarzinejad, H., and Dianat, M. (2016). Duodenal Acidification Stimulates Gastric H2S Release through Upregulating mRNA Expression of Cystathionine Gamma Lyase. Physiol. Pharmacol. 20 (1), 57-62.

Mard, S. A., Ahmadi, I., Ahangarpour, A., Gharib-Naseri, M. K., and Badavi, M. (2016). Delayed Gastric Emptying in Diabetic Rats Caused by Decreased Expression of Cystathionine Gamma Lyase and H2S Synthesis:in Vitroandin Vivostudies. Neurogastroenterol. Motil. 28 (11), 1677-1689. doi:10.1111/ nmo. 12867

Mard, S. A., Veisi, A., Ahangarpour, A., and Gharib-Naseri, M. K. (2015). Gastric Acid Induces Mucosal H2S Release in Rats by Upregulating mRNA and Protein Expression of Cystathionine Gamma Lyase. J. Physiol. Sci. 65 (6), 545-554. doi:10.1007/s12576-015-0392-5

Martinez-Cuesta, M. A., Barrachina, M. D., Pique, J. M., Whittle, B. J., and Esplugues, J. V. (1992). The Role of Nitric Oxide and Platelet-Activating Factor in the Inhibition by Endotoxin of Pentagastrin-Stimulated Gastric Acid Secretion. Eur. J. Pharmacol. 218 (2-3), 351-354. doi:10.1016/0014-2999(92)90191-6

Marzullo, P., Verti, B., Savia, G., Walker, G. E., Guzzaloni, G., Tagliaferri, M., et al. (2004). The Relationship between Active Ghrelin Levels and Human Obesity Involves Alterations in Resting Energy Expenditure. J. Clin. Endocrinol. Metab. 89 (2), 936-939. doi:10.1210/jc.2003-031328

Masclee, A. A., Jansen, J. B., Corstens, F. H., and Lamers, C. B. (1989). Reversible Gall Bladder Dysfunction in Severe Pancreatic Insufficiency. Gut 30 (6), 866-872. doi:10.1136/gut.30.6.866

Masuda, Y., Tanaka, T., Inomata, N., Ohnuma, N., Tanaka, S., Itoh, Z., et al. (2000). Ghrelin Stimulates Gastric Acid Secretion and Motility in Rats. Biochem. Biophysical Res. Commun. 276 (3), 905-908. doi:10.1006/bbrc.2000.3568

Matsubara, J., Sugiyama, S., Sugamura, K., Nakamura, T., Fujiwara, Y., Akiyama, E., et al. (2012). A Dipeptidyl Peptidase-4 Inhibitor, Des-Fluoro-Sitagliptin, Improves Endothelial Function and Reduces Atherosclerotic Lesion Formation in Apolipoprotein E-Deficient Mice. J. Am. Coll. Cardiol. 59 (3), 265-276. doi:10.1016/j.jacc.2011.07.053

Matsuda, N. M., Miller, S. M., and Szurszewski, J. H. (2010). Heme-oxygenase-2 Immunolabelling in Pig Jejunum. Acta Histochem. 112 (4), 402-406. doi:10.1016/j.acthis.2009.01.001

McLaughlin, J., Lucà, M. G., Jones, M. N., D’Amato, M., Dockray, G. J., and Thompson, D. G. (1999). Fatty Acid Chain Length Determines Cholecystokinin Secretion and Effect on Human Gastric Motility. Gastroenterology 116 (1), 46-53. doi:10.1016/s0016-5085(99)70227-1

McQueen, J. M., and Heck, A. M. (2002). Secretin for the Treatment of Autism. Ann. Pharmacother. 36 (2), 305-311. doi:10.1345/aph.19113

Medani, M., Collins, D., Docherty, N. G., Baird, A. W., O'Connell, P. R., and Winter, D. C. (2011). Emerging Role of Hydrogen Sulfide in Colonic Physiology and Pathophysiology. Inflamm. Bowel Dis. 17 (7), 1620-1625. doi:10.1002/ ibd. 21528 
Medeiros, J. V., Bezerra, V. H., Lucetti, L. T., Lima-Junior, R. C., Barbosa, A. L., Tavares, B. M., et al. (2012). Role of KATP Channels and TRPV1 Receptors in Hydrogen Sulfide-Enhanced Gastric Emptying of Liquid in Awake Mice. Eur. J. Pharmacol. 693 (1-3), 57-63. doi:10.1016/ j.ejphar.2012.07.004

Meece, J. (2017). The Role of the Pharmacist in Managing Type 2 Diabetes with Glucagon-like Peptide-1 Receptor Agonists as Add-On Therapy. Adv. Ther. 34 (3), 638-657. doi:10.1007/s12325-017-0491-1

Meulemans, A. L., Wellens, A. L. Y., and Schuurkes, J. A. J. (1997). Gastric Secretion but Not Nitric Oxide Is Involved in Pentagastrin-Induced Gastric Relaxation in Conscious Dogs. Neurogastroenterol Motil. 9 (1), 49-54. doi:10.1046/j.1365-2982.1997.d01-7.x

Miller, L. J., and Gao, F. (2008). Structural Basis of Cholecystokinin Receptor Binding and Regulation. Pharmacol. Ther. 119 (1), 83-95. doi:10.1016/ j.pharmthera.2008.05.001

Miller, S. M., Reed, D., Sarr, M. G., Farrugia, G., and Szurszewski, J. H. (2001). Haem Oxygenase in Enteric Nervous System of Human Stomach and Jejunum and Co-localization with Nitric Oxide Synthase. Neurogastroenterol Motil. 13 (2), 121-131. doi:10.1046/j.1365-2982.2001.00255.x

Mitznegg, P., Bloom, S. R., Domschke, W., Haecki, W. H., Domschke, S., Belohlavek, D., et al. (1977). Effect of Secretin on Plasma Motilin in Man. Gut 18 (6), 468-471. doi:10.1136/gut.18.6.468

Mitznegg, P., Domschke, W., Wunsch, E., Bloom, S. R., Domschke, S., and Demling, L. (1976). Release of Motilin after Duodenal Acidification. The Lancet 307 (7965), 888-889. doi:10.1016/s0140-6736(76)92101-2

Mizumoto, A., Muramatsu, S., Yamada, T., and Itoh, Z. (1997). Effect of Nitric Oxide Synthase Inhibition on Plasma Motilin Release in Fasted Dogs. Regul. Peptides 71 (1), 9-14. doi:10.1016/s0167-0115(97)01004-5

Moloudi, R., Nabavizadeh, F., Nahrevanian, H., and Hassanzadeh, G. (2011). Effect of Different Doses of GLP-2 (Teduglutide) on Acute Esophageal Lesion Due to Acid-Pepsin Perfusion in Male Rats. Peptides 32 (10), 2086-2090. doi:10.1016/ j.peptides.2011.09.004

Montagnani, M., Ravichandran, L. V., Chen, H., Esposito, D. L., and Quon, M. J. (2002). Insulin Receptor Substrate-1 and Phosphoinositide-dependent Kinase1 Are Required for Insulin-Stimulated Production of Nitric Oxide in Endothelial Cells. Mol. Endocrinol. 16 (8), 1931-1942. doi:10.1210/me.20020074

Moreno, C., Mistry, M., and Roman, R. J. (2002). Renal Effects of Glucagon-like Peptide in Rats. Eur. J. Pharmacol. 434 (3), 163-167. doi:10.1016/s00142999(01)01542-4

Morley, J. E., Farr, S. A., Sell, R. L., Hileman, S. M., and Banks, W. A. (2011). Nitric Oxide Is a central Component in Neuropeptide Regulation of Appetite. Peptides 32 (4), 776-780. doi:10.1016/j.peptides.2010.12.015

Morton, M. F., Welsh, N. J., Tavares, I. A., and Shankley, N. P. (2002). Pharmacological Characterization of Cholecystokinin Receptors Mediating Contraction of Human Gallbladder and Ascending colon. Regul. Peptides 105 (1), 59-64. doi:10.1016/s0167-0115(01)00383-4

Motterlini, R., Gonzales, A., Foresti, R., Clark, J. E., Green, C. J., and Winslow, R. M. (1998). Heme Oxygenase-1-Derived Carbon Monoxide Contributes to the Suppression of Acute Hypertensive Responses In Vivo. Circ. Res. 83 (5), 568-577. doi:10.1161/01.res.83.5.568

Moustafa, A., and Habara, Y. (2014). A Novel Role for Carbon Monoxide as a Potent Regulator of Intracellular Ca2+and Nitric Oxide in Rat Pancreatic Acinar Cells. Am. J. Physiology-Cell Physiol. 307 (11), C1039-C1049. doi:10.1152/ajpcell.00252.2014

Moustafa, A., and Habara, Y. (2014). Hydrogen Sulfide Regulates Ca2+ Homeostasis Mediated by Concomitantly Produced Nitric Oxide via a Novel Synergistic Pathway in Exocrine Pancreas. Antioxid. Redox Signaling 20 (5), 747-758. doi:10.1089/ars.2012.5108

Naito, Y., Takagi, T., Uchiyama, K., Katada, K., and Yoshikawa, T. (2016). Multiple Targets of Carbon Monoxide Gas in the Intestinal Inflammation. Arch. Biochem. Biophys. 595, 147-152. doi:10.1016/j.abb.2015.06.020

Nakazato, M., Murakami, N., Date, Y., Kojima, M., Matsuo, H., Kangawa, K., et al. (2001). A Role for Ghrelin in the central Regulation of Feeding. Nature 409 (6817), 194-198. doi:10.1038/35051587

Ng, Y. K., Xue, Y. D., and Wong, P. T. H. (1999). Different Distributions of Nitric Oxide Synthase-Containing Neurons in the Mouse and Rat Hypothalamus. Nitric Oxide 3 (5), 383-392. doi:10.1006/niox.1999.0247
Nishijima, I., Yamagata, T., Spencer, C. M., Weeber, E. J., Alekseyenko, O., Sweatt, J. D., et al. (2006). Secretin Receptor-Deficient Mice Exhibit Impaired Synaptic Plasticity and Social Behavior. Hum. Mol. Genet. 15 (21), 3241-3250. doi: $10.1093 / \mathrm{hmg} / \mathrm{ddl} 402$

Nishimori, I., Kamakura, M., Fujikawa-Adachi, K., Nojima, M., Onishi, S., Hollingsworth, M. A., et al. (1999). Cholecystokinin A and B Receptor mRNA Expression in Human Pancreas. Pancreas 19 (2), 109-113. doi:10.1097/00006676-199908000-00001

Nojima, K., Sumii, K., Sumii, M., Okahara, S., Haruma, K., Yoshihara, M., et al. (2000). Acid-sensitive and Alkaline-Sensitive Sensory Neurons Regulate $\mathrm{pH}$ Dependent Gastrin Secretion in Rat. Dig. Dis. Sci. 45 (6), 1217-1226. doi:10.1023/a:1005570507166

Nonogaki, K. (2008). Ghrelin and Feedback Systems. Vitam Horm. 77, 149-170. doi:10.1016/S0083-6729(06)77007-8

Nystrom, T., Gonon, A. T., Sjoholm, A., and Pernow, J. (2005). Glucagon-like Peptide-1 Relaxes Rat Conduit Arteries via an Endothelium-independent Mechanism. Regul. Pept. 125 (1-3), 173-177. doi:10.1016/j.regpep.2004.08.024

Nyström, T., Gutniak, M. K., Zhang, Q., Zhang, F., Holst, J. J., Ahrén, B., et al. (2004). Effects of Glucagon-like Peptide-1 on Endothelial Function in Type 2 Diabetes Patients with Stable Coronary Artery Disease. Am. J. PhysiologyEndocrinology Metab. 287 (6), E1209-E1215. doi:10.1152/ajpendo.00237.2004

Okumura, H., Nagaya, N., Enomoto, M., Nakagawa, E., Oya, H., and Kangawa, K. (2002). Vasodilatory Effect of Ghrelin, an Endogenous Peptide from the Stomach. J. Cardiovasc. Pharmacol. 39 (6), 779-783. doi:10.1097/00005344200206000-00001

Pan, K. T., Leonardi, G. S., and Croxford, B. (2020). Factors Contributing to CO Uptake and Elimination in the Body: A Critical Review. Int. J. Environ. Res. Public Health 17 (2), 528. doi:10.3390/ijerph17020528

Patel, A. G., Toyama, M. T., Nguyen, T. N., Cohen, G. A., Ignarro, L. J., Reber, H. A., et al. (1995). Role of Nitric Oxide in the Relationship of Pancreatic Blood Flow and Exocrine Secretion in Cats. Gastroenterology 108 (4), 1215-1220. doi:10.1016/0016-5085(95)90222-8

Pawlik, W. W., Gustaw, P., Czarnobilski, K., and Konturek, S. J. (1987). Systemic Circulatory Effects of Pentagastrin. Acta Physiol. Pol. 38 (5), 418-424.

Peeters, T. L., Bormans, V., and Vantrappen, G. (1988). Comparison of Motilin Binding to Crude Homogenates of Human and Canine Gastrointestinal Smooth Muscle Tissue. Regul. Peptides 23 (2), 171-182. doi:10.1016/01670115(88)90025-0

Peeters, T. L., Muls, E., Janssens, J., Urbain, J.-L., Bex, M., Van Cutsem, E., et al. (1992). Effect of Motilin on Gastric Emptying in Patients with Diabetic Gastroparesis. Gastroenterology 102 (1), 97-101. doi:10.1016/0016-5085(92) 91788-6

Pichette, J., and Gagnon, J. (2016). Implications of Hydrogen Sulfide in Glucose Regulation: How H2S Can Alter Glucose Homeostasis through Metabolic Hormones. Oxid Med. Cel Longev 2016, 3285074. doi:10.1155/2016/3285074

Pichette, J., Fynn-Sackey, N., and Gagnon, J. (2017). Hydrogen Sulfide and Sulfate Prebiotic Stimulates the Secretion of GLP-1 and Improves Glycemia in Male Mice. Endocrinology 158 (10), 3416-3425. doi:10.1210/en.2017-00391

Pini, A., Garella, R., Idrizaj, E., Calosi, L., Baccari, M. C., and Vannucchi, M. G. (2016). Glucagon-like Peptide 2 Counteracts the Mucosal Damage and the Neuropathy Induced by Chronic Treatment with Cisplatin in the Mouse Gastric Fundus. Neurogastroenterol. Motil. 28 (2), 206-216. doi:10.1111/ nmo.12712

Pique, J. M., Esplugues, J. V., and Whittle, B. J. R. (1992). Endogenous Nitric Oxide as a Mediator of Gastric Mucosal Vasodilatation during Acid Secretion. Gastroenterology 102 (1), 168-174. doi:10.1016/0016-5085(92)91797-8

Powell, C. R., Dillon, K. M., and Matson, J. B. (2018). A Review of Hydrogen Sulfide (H2S) Donors: Chemistry and Potential Therapeutic Applications. Biochem. Pharmacol. 149, 110-123. doi:10.1016/j.bcp.2017.11.014

Premen, A. J., Kvietys, P. R., and Granger, D. N. (1985). Postprandial Regulation of Intestinal Blood Flow: Role of Gastrointestinal Hormones. Am. J. PhysiologyGastrointestinal Liver Physiol. 249 (2 Pt 1), G250-G255. doi:10.1152/ ajpgi.1985.249.2.g250

Publicover, N. G., Hammond, E. M., and Sanders, K. M. (1993). Amplification of Nitric Oxide Signaling by Interstitial Cells Isolated from Canine colon. Proc. Natl. Acad. Sci. 90 (5), 2087-2091. doi:10.1073/pnas.90.5.2087

Qader, S. S., Lundquist, I., Ekelund, M., Håkanson, R., and Salehi, A. (2005). Ghrelin Activates Neuronal Constitutive Nitric Oxide Synthase in Pancreatic 
Islet Cells while Inhibiting Insulin Release and Stimulating Glucagon Release. Regul. Peptides 128 (1), 51-56. doi:10.1016/j.regpep.2004.12.018

Quintana, E., García-Zaragozá, E., Angeles Martínez-Cuesta, M., Calatayud, S., Esplugues, J. V., and Barrachina, M. D. (2001). A Cerebral Nitrergic Pathway Modulates Endotoxin-Induced Changes in Gastric Motility. Br. J. Pharmacol. 134 (2), 325-332. doi:10.1038/sj.bjp.0704258

Qvist, N., Oster-Jorgensen, E., Pedersen, S. A., Rasmussen, L., Hovendal, C., and Holst, J. J. (1995). Increases in Plasma Motilin Follow Each Episode of Gallbladder Emptying during the Interdigestive Period, and Changes in Serum Bile Acid Concentration Correlate to Plasma Motilin. Scand. J. Gastroenterol. 30 (2), 122-127. doi:10.3109/00365529509093249

Rehfeld, J. F. (1998). The New Biology of Gastrointestinal Hormones. Physiol. Rev. 78 (4), 1087-1108. doi:10.1152/physrev.1998.78.4.1087

Reubi, J., Waser, B., Laderach, U., Stettler, C., Friess, H., Halter, F., et al. (1997). Localization of Cholecystokinin A and Cholecystokinin B-Gastrin Receptors in the Human Stomach. Gastroenterology 112 (4), 1197-1205. doi:10.1016/s00165085(97)70131-8

Robbins, R. A., and Grisham, M. B. (1997). Nitric Oxide. Int. J. Biochem. Cel Biol. 29 (6), 857-860. doi:10.1016/s1357-2725(96)00167-7

Rodríguez-pacheco, F., Luque, R. M., García-navarro, S., Gracia-Navarro, F., Castaño, J. P., and Malagón, M. M. (2005). Ghrelin Induces Growth Hormone (GH) Secretion via Nitric Oxide (NO)/cGMP Signaling. Ann. N. Y Acad. Sci. 1040, 452-453. doi:10.1196/annals.1327.087

Rotondo, A., Amato, A., Lentini, L., Baldassano, S., and Mulè, F. (2011). Glucagonlike Peptide-1 Relaxes Gastric Antrum through Nitric Oxide in Mice. Peptides 32 (1), 60-64. doi:10.1016/j.peptides.2010.09.028

Rowland, K. J., and Brubaker, P. L. (2011). The "cryptic" Mechanism of Action of Glucagon-like Peptide-2. Am. J. Physiology-Gastrointestinal Liver Physiol. 301 (1), G1-G8. doi:10.1152/ajpgi.00039.2011

Ruiz-Gayo, M., González, M. C., and Fernández-Alfonso, S. (2006). Vasodilatory Effects of Cholecystokinin: New Role for an Old Peptide?. Regul. Peptides 137 (3), 179-184. doi:10.1016/j.regpep.2006.06.006

Ryan, D., and Acosta, A. (2015). GLP -1 Receptor Agonists: Nonglycemic Clinical Effects in Weight Loss and beyond. Obesity 23 (6), 1119-1129. doi:10.1002/ oby. 21107

Saia, R. S., Mestriner, F. L., Bertozi, G., Cunha, F. Q., and Carnio, E. C. (2014). Cholecystokinin Inhibits Inducible Nitric Oxide Synthase Expression by Lipopolysaccharide-Stimulated Peritoneal Macrophages. Mediators Inflamm. 2014, 896029. doi:10.1155/2014/896029

Saia, R. S., Bertozi, G., Mestriner, F. L., Antunes-Rodrigues, J., Queiróz Cunha, F., and Cárnio, E. C. (2013). Cardiovascular and Inflammatory Response to Cholecystokinin during Endotoxemic Shock. Shock 39 (1), 104-113. doi:10.1097/shk.0b013e3182793e2e

Salaga, M., Mokrowiecka, A., Zielinska, M., Malecka-Panas, E., Kordek, R., Kamysz, E., et al. (2017). New Peptide Inhibitor of Dipeptidyl Peptidase IV, EMDB-1 Extends the Half-Life of GLP-2 and Attenuates Colitis in Mice after Topical Administration. J. Pharmacol. Exp. Ther. 363 (1), 92-103. doi:10.1124/ jpet.117.242586

Sánchez-Fernández, C., González, C., Mercer, L. D., Beart, P. M., Ruiz-Gayo, M., and Fernández-Alfonso, M. S. (2003). Cholecystokinin Induces Cerebral Vasodilatation via Presynaptic CCK2 Receptors: New Implications for the Pathophysiology of Panic. J. Cereb. Blood Flow Metab. 23 (3), 364-370. doi:10.1097/01.WCB.0000043948.67811.8F

Sanchez-Fernandez, C., Gonzalez, M. C., Beart, P. M., Mercer, L. D., Ruiz-Gayo, M., and Fernandez-Alfonso, M. S. (2004). A Novel Role for Cholecystokinin: Regulation of Mesenteric Vascular Resistance. Regul. Pept. 121 (1-3), 145-153. doi:10.1016/j.regpep.2004.04.018

Sanders, M. J., Amirian, D. A., Ayalon, A., and Soll, A. H. (1983). Regulation of Pepsinogen Release from Canine Chief Cells in Primary Monolayer Culture. Am. J. Physiology-Gastrointestinal Liver Physiol. 245 (5 Pt 1), G641-G646. doi:10.1152/ajpgi.1983.245.5.g641

Sarna, S. K., Otterson, M. F., Ryan, R. P., and Cowles, V. E. (1993). Nitric Oxide Regulates Migrating Motor Complex Cycling and its Postprandial Disruption. Am. J. Physiology-Gastrointestinal Liver Physiol. 265 (4 Pt 1), G759-G766. doi:10.1152/ajpgi.1993.265.4.g759

Schlatter, P., Beglinger, C., Drewe, J., and Gutmann, H. (2007). Glucagon-like Peptide 1 Receptor Expression in Primary Porcine Proximal Tubular Cells. Regul. Pept. 141 (1-3), 120-128. doi:10.1016/j.regpep.2006.12.016
Schmidt, W. E., Creutzfeldt, W., Schleser, A., Choudhury, A. R., Nustede, R., Hocker, M., et al. (1991). Role of CCK in Regulation of Pancreaticobiliary Functions and GI Motility in Humans: Effects of Loxiglumide. Am. J. Physiology-Gastrointestinal Liver Physiol. 260 (2 Pt 1), G197-G206. doi:10.1152/ajpgi.1991.260.2.g197

Schmitz, F., Goke, M. N., Otte, J. M., Schrader, H., Reimann, B., Kruse, M. L., et al. (2001). Cellular Expression of CCK-A and CCK-B/gastrin Receptors in Human Gastric Mucosa. Regul. Pept. 102 (2-3), 101-110. doi:10.1016/s0167-0115(01) 00307-x

Schuurkes, J. A., and Meulemans, A. L. (1994). Nitric Oxide and Gastric Relaxation. Dig. Dis. Sci. 39 (12 Suppl. l), 79S-81S. doi:10.1007/bf02300378

Seidler, U. E. (2013). Gastrointestinal HCO3- Transport and Epithelial protection in the Gut: New Techniques, Transport Pathways and Regulatory Pathways. Curr. Opin. Pharmacol. 13 (6), 900-908. doi:10.1016/j.coph.2013.10.001

Sélley, E., Kun, S., Szijártó, I., Laczy, B., Kovács, T., Fülöp, F., et al. (2014). Exenatide Induces Aortic Vasodilation Increasing Hydrogen Sulphide, Carbon Monoxide and Nitric Oxide Production. Cardiovasc. Diabetol. 13, 69. doi:10.1186/14752840-13-69

Shibuya, N., Tanaka, M., Yoshida, M., Ogasawara, Y., Togawa, T., Ishii, K., et al. (2009). 3-Mercaptopyruvate Sulfurtransferase Produces Hydrogen Sulfide and Bound Sulfane Sulfur in the Brain. Antioxid. Redox Signaling 11 (4), 703-714. doi:10.1089/ars.2008.2253

Shiiya, T., Nakazato, M., Mizuta, M., Date, Y., Mondal, M. S., Tanaka, M., et al. (2002). Plasma Ghrelin Levels in Lean and Obese Humans and the Effect of Glucose on Ghrelin Secretion. J. Clin. Endocrinol. Metab. 87 (1), 240-244. doi:10.1210/jcem.87.1.8129

Shimizu, I., Hirota, M., Ohboshi, C., and Shima, K. (1987). Identification and Localization of Glucagon-like Peptide-1 and its Receptor in Rat Brain. Endocrinology 121 (3), 1076-1082. doi:10.1210/endo-121-3-1076

Shinde, U. A., Desai, K. M., Yu, C., and Gopalakrishnan, V. (2005). Nitric Oxide Synthase Inhibition Exaggerates the Hypotensive Response to Ghrelin: Role of Calcium-Activated Potassium Channels. J. Hypertens. 23 (4), 779-784. doi:10.1097/01.hjh.0000163146.20330.bc

Shintani, M., Ogawa, Y., Ebihara, K., Aizawa-Abe, M., Miyanaga, F., Takaya, K., et al. (2001). Ghrelin, an Endogenous Growth Hormone Secretagogue, Is a Novel Orexigenic Peptide that Antagonizes Leptin Action through the Activation of Hypothalamic Neuropeptide Y/Y1 Receptor Pathway. Diabetes 50 (2), 227-232. doi:10.2337/diabetes.50.2.227

Sibilia, V., Rindi, G., Pagani, F., Rapetti, D., Locatelli, V., Torsello, A., et al. (2003). Ghrelin Protects against Ethanol-Induced Gastric Ulcers in Rats: Studies on the Mechanisms of Action. Endocrinology 144 (1), 353-359. doi:10.1210/en.2002220756

Sitniewska, E. M., Wiśniewska, R. J., and Wiśniewski, K. (2000). Influence of Nitric Oxide on the Cardiovascular Action of Secretin in Intact Rats. Part A. Does Nitric Oxide Influence the Effect of Secretin on Arterial Blood Pressure?. Pol. J. Pharmacol. 52 (5), 367-373.

Sitniewska, E. M., Wiśniewska, R. J., and Wiśniewski, K. (2000). Influence of Nitric Oxide on the Cardiovascular Action of Secretin in Intact Rats. Part B. Does Nitric Oxide Influence the Effect of Secretin on Isolated Heart Function?. Pol. J. Pharmacol. 52 (5), 375-381.

Sitniewska, E. M., and Wiśniewska, R. J. (2001). Influence of Secretin and L-NAME on Vascular Permeability in the Coronary Circulation of Intact and Diabetic Rats. Regul. Peptides 96 (3), 105-111. doi:10.1016/s01670115(00)00131-2

Sitniewska, E. M., Wiśniewska, R. J., and Wiśniewski, K. (2002). Diabetes-induced Changes of Nitric Oxide Influence on the Cardiovascular Action of Secretin. Regul. Peptides 105 (3), 163-172. doi:10.1016/s0167-0115(02)00018-6

Slade, E., Williams, L., and Gagnon, J. (2018). Hydrogen Sulfide Suppresses Ghrelin Secretion In Vitro and Delays Postprandial Ghrelin Secretion while Reducing Appetite in Mice. Physiol. Rep. 6 (19), e13870. doi:10.14814/phy2.13870

Smits, M. M., Muskiet, M. H. A., Tonneijck, L., Kramer, M. H. H., Diamant, M., van Raalte, D. H., et al. (2015). GLP-1 Receptor Agonist Exenatide Increases Capillary Perfusion Independent of Nitric Oxide in Healthy Overweight Men. Atvb 35 (6), 1538-1543. doi:10.1161/atvbaha.115.305447

Steiger, C., Uchiyama, K., Takagi, T., Mizushima, K., Higashimura, Y., Gutmann, M., et al. (2016). Prevention of Colitis by Controlled Oral Drug Delivery of Carbon Monoxide. J. Controlled Release 239, 128-136. doi:10.1016/ j.jconrel.2016.08.030 
Sternini, C., Anselmi, L., and Rozengurt, E. (2008). Enteroendocrine Cells: a Site of 'taste' in Gastrointestinal Chemosensing. Curr. Opin. Endocrinol. Diabetes Obes. 15 (1), 73-78. doi:10.1097/med.0b013e3282f43a73

Stone, J. R., and Marletta, M. A. (1994). Soluble Guanylate Cyclase from Bovine Lung: Activation with Nitric Oxide and Carbon Monoxide and Spectral Characterization of the Ferrous and Ferric States. Biochemistry 33 (18), 5636-5640. doi:10.1021/bi00184a036

Stroff, T., Lambrecht, N., and Peskar, B. M. (1994). Nitric Oxide as Mediator of the Gastroprotection by Cholecystokinin-8 and Pentagastrin. Eur. J. Pharmacol. 260 (1), R1-R2. doi:10.1016/0014-2999(94)90019-1

Sugawara, K., Isaza, J., Curt, J. R., and Woodward, E. R. (1970). Distension of the Pyloric Antrum as a Stimulus for Gastrin Release. Arch. Surg. 100 (2), 201-204. doi:10.1001/archsurg. 1970.01340200089019

Sullivan, C. N., Raboin, S. J., Gulley, S., Sinzobahamvya, N. T., Green, G. M., Reeve, J. R., Jr., et al. (2007). Endogenous Cholecystokinin Reduces Food Intake and Increases Fos-like Immunoreactivity in the Dorsal Vagal Complex but Not in the Myenteric Plexus by CCK1 Receptor in the Adult Rat. Am. J. PhysiologyRegulatory, Integr. Comp. Physiol. 292 (3), R1071-R1080. doi:10.1152/ ajpregu.00490.2006

Sun, F., Wu, S., Guo, S., Yu, K., Yang, Z., Li, L., et al. (2015). Impact of GLP-1 Receptor Agonists on Blood Pressure, Heart Rate and Hypertension Among Patients with Type 2 Diabetes: A Systematic Review and Network MetaAnalysis. Diabetes Res. Clin. Pract. 110 (1), 26-37. doi:10.1016/ j.diabres.2015.07.015

Suzuki, H., Matsuzaki, J., and Hibi, T. (2011). Ghrelin and Oxidative Stress in Gastrointestinal Tract. J. Clin. Biochem. Nutr. 48 (2), 122-125. doi:10.3164/ jcbn.10-16GFR

Suzuki, H., Kuwano, H., Mochiki, E., Haga, N., Shimura, T., Nomoto, K., et al. (2003). Effect of Motilin on Endogenous Release of Insulin in Conscious Dogs in the Fed State. Dig. Dis. Sci. 48 (12), 2263-2270. doi:10.1023/b: ddas.0000007861.91075.b3

Suzuki, H., Mochiki, E., Haga, N., Satoh, M., Mizumoto, A., and Itoh, Z. (1998). Motilin Controls Cyclic Release of Insulin through Vagal Cholinergic Muscarinic Pathways in Fasted Dogs. Am. J. Physiology-Gastrointestinal Liver Physiol. 274 (1), G87-G95. doi:10.1152/ajpgi.1998.274.1.g87

Suzuki, K., Sagara, M., Aoki, C., Tanaka, S., and Aso, Y. (2017). Clinical Implication of Plasma Hydrogen Sulfide Levels in Japanese Patients with Type 2 Diabetes. Intern. Med. 56 (1), 17-21. doi:10.2169/internalmedicine. 56.7403

Svenberg, T., Nilsson, I., Samuelson, K., and Welbourn, R. D. (1984). Studies on the Causal Relationship between Gall-Bladder Emptying and Motilin Release in Man. Acta Chir Scand. Suppl. 520, 59-61.

Tack, J., Deloose, E., Ang, D., Scarpellini, E., Vanuytsel, T., Van Oudenhove, L., et al. (2016). Motilin-induced Gastric Contractions Signal Hunger in Man. Gut 65 (2), 214-224. doi:10.1136/gutjnl-2014-308472

Tack, J., Demedts, I., Meulemans, A., Schuurkes, J., and Janssens, J. (2002). Role of Nitric Oxide in the Gastric Accommodation Reflex and in Meal Induced Satiety in Humans. Gut 51 (2), 219-224. doi:10.1136/gut.51.2.219

Takagi, T., Naito, Y., Uchiyama, K., Mizuhima, K., Suzuki, T., Horie, R., et al. (2016). Carbon Monoxide Promotes Gastric Wound Healing in Mice via the Protein Kinase C Pathway. Free Radic. Res. 50 (10), 1098-1105. doi:10.1080/ 10715762.2016.1189546

Takahashi, A., Tomomasa, T., Kaneko, H., Hatori, R., Ishige, T., Suzuki, M., et al. (2005). In Vivo recording of Colonic Motility in Conscious Rats with Deficiency of Interstitial Cells of Cajal, with Special Reference to the Effects of Nitric Oxide on Colonic Motility. J. Gastroenterol. 40 (11), 1043-1048. doi:10.1007/s00535005-1688-7

Takahashi, N., Kozai, D., and Mori, Y. (2012). TRP Channels: Sensors and Transducers of Gasotransmitter Signals. Front. Physiol. 3, 324. doi:10.3389/ fphys.2012.00324

Takeuchi, K., Ise, F., Takahashi, K., Aihara, E., and Hayashi, S. (2015). H2Sinduced HCO3- Secretion in the Rat Stomach - Involvement of Nitric Oxide, Prostaglandins, and Capsaicin-Sensitive Sensory Neurons. Nitric Oxide 46, 157-164. doi:10.1016/j.niox.2014.11.001

Tanaka, T., Mizumoto, A., and Itoh, Z. (2005). Effects of Nitric Oxide Synthase Inhibitor on the Digestive System Measured by Simultaneous Monitoring of Gastric Motility, Gastric Emptying Activity and Postprandial Pancreaticobiliary Secretion in Dogs. Exp. Anim. 54 (4), 309-317. doi:10.1538/expanim.54.309
Tang, S.-t., Zhang, Q., Tang, H.-q., Wang, C.-j., Su, H., Zhou, Q., et al. (2016). Effects of Glucagon-like Peptide-1 on Advanced Glycation EndproductInduced Aortic Endothelial Dysfunction in Streptozotocin-Induced Diabetic Rats: Possible Roles of Rho Kinase- and AMP Kinase-Mediated Nuclear Factor кB Signaling Pathways. Endocrine 53 (1), 107-116. doi:10.1007/s12020-0150852-y

Tatemichi, M., Ogura, T., Sakurazawa, N., Nagata, H., Sugita, M., and Esumi, H. (2003). Roles of Inducible Nitric Oxide Synthase in the Development and Healing of Experimentally Induced Gastric Ulcers. Int. J. Exp. Pathol. 84 (5), 213-220. doi:10.1111/j.1365-2613.2003.00357.x

Tatsuguchi, A., Miyake, K., Gudis, K., Futagami, S., Tsukui, T., Wada, K., et al. (2004). Effect of Helicobacter pylori Infection on Ghrelin Expression in Human Gastric Mucosa. Am. J. Gastroenterol. 99 (11), 2121-2127. doi:10.1111/j.15720241.2004.30291.x

Tesauro, M., Schinzari, F., Iantorno, M., Rizza, S., Melina, D., Lauro, D., et al. (2005). Ghrelin Improves Endothelial Function in Patients with Metabolic Syndrome. Circulation 112 (19), 2986-2992. doi:10.1161/ circulationaha.105.553883

Tesauro, M., Schinzari, F., Rovella, V., Di Daniele, N., Lauro, D., Mores, N., et al. (2009). Ghrelin Restores the Endothelin 1/nitric Oxide Balance in Patients with Obesity-Related Metabolic Syndrome. Hypertension 54 (5), 995-1000. doi:10.1161/hypertensionaha.109.137729

Thomson, S. C., Kashkouli, A., Liu, Z. Z., and Singh, P. (2017). Renal Hemodynamic Effects of Glucagon-like Peptide-1 Agonist Are Mediated by Nitric Oxide but Not Prostaglandin. Am. J. Physiology-Renal Physiol. 313 (4), F854-F858. doi:10.1152/ajprenal.00258.2017

Thomson, S. C., Kashkouli, A., and Singh, P. (2013). Glucagon-like Peptide-1 Receptor Stimulation Increases GFR and Suppresses Proximal Reabsorption in the Rat. Am. J. Physiology-Renal Physiol. 304 (2), F137-F144. doi:10.1152/ ajprenal.00064.2012

Thulesen, J. (2004). Glucagon-like Peptide 2 (GLP-2), an Intestinotrophic Mediator. Curr. Protein Pept. Sci. 5 (1), 51-65. doi:10.2174/1389203043486946

Thulin, L., and Olsson, P. (1973). Effects of Pure Natural Cholecystokinin on Splanchnic Circulation in the Dog. Acta Chir Scand. 139 (8), 681-686.

Tian, F., Ling, Y., Chen, Y., and Wang, Z. (2017). Effects of CCK-8 and Cystathionine $\gamma$-Lyase/Hydrogen Sulfide System on Acute Lung Injury in Rats. Inflammation 40 (1), 174-183. doi:10.1007/s10753-016-0466-4

Toft-Nielsen, M.-B., Damholt, M. B., Madsbad, S., Hilsted, L. M., Hughes, T. E., Michelsen, B. K., et al. (2001). Determinants of the Impaired Secretion of Glucagon-like Peptide-1 in Type 2 Diabetic Patients. J. Clin. Endocrinol. Metab. 86 (8), 3717-3723. doi:10.1210/jcem.86.8.7750

Tolessa, T., Naslund, E., and Hellstrom, P. M. (2001). The Inhibitory Mechanism of GLP-1, but Not Glucagon, on Fasted Gut Motility Is Dependent on the L-Arginine/nitric Oxide Pathway. Regul. Pept. 98 (1-2), 33-40. doi:10.1016/ s0167-0115(00)00220-2

Tolessa, T., Gutniak, M., Holst, J. J., Efendic, S., and Hellström, P. M. (1998). Inhibitory Effect of Glucagon-like Peptide-1 on Small Bowel Motility. Fasting but Not Fed Motility Inhibited via Nitric Oxide Independently of Insulin and Somatostatin. J. Clin. Invest. 102 (4), 764-774. doi:10.1172/jci942

Tortorella, C., Macchi, C., Spinazzi, R., Malendowicz, L. K., Trejter, M., and Nussdorfer, G. G. (2003). Ghrelin, an Endogenous Ligand for the Growth Hormone-Secretagogue Receptor, Is Expressed in the Human Adrenal Cortex. Int. J. Mol. Med. 12 (2), 213-217.

Ueda, K., Ueyama, T., Oka, M., Ito, T., Tsuruo, Y., and Ichinose, M. (2009). Polaprezinc (Zinc L-Carnosine) Is a Potent Inducer of Anti-oxidative Stress Enzyme, Heme Oxygenase (HO)-1 - a New Mechanism of Gastric Mucosal protection. J. Pharmacol. Sci. 110 (3), 285-294. doi:10.1254/jphs.09056fp

Uribe, R. M., Lee, S., and Rivier, C. (1999). Endotoxin Stimulates Nitric Oxide Production in the Paraventricular Nucleus of the Hypothalamus through Nitric Oxide Synthase I: Correlation with Hypothalamic-Pituitary-Adrenal Axis Activation1. Endocrinology 140 (12), 5971-5981. doi:10.1210/endo.140.12.7170

Vadokas, B., Ludtke, F.-E., Lepsien, G., Golenhofen, K., and Mandrek, K. (1997). Effects of Gastrin-Releasing Peptide (GRP) on the Mechanical Activity of the Human Ileocaecal Region In Vitro. Neurogastroenterol Motil. 9 (4), 265-270. doi:10.1046/j.1365-2982.1997.d01-59.x

Vagne, M., and Andre, C. (1971). The Effect of Secretin on Gastric Emptying in Man. Gastroenterology 60 (3), 421-424. doi:10.1016/s0016-5085(71)80122-1 
Valenzuela, J. E., Walsh, J. H., and Isenberg, J. I. (1976). Effect of Gastrin on Pancreatic Enzyme Secretion and Gallbladder Emptying in Man. Gastroenterology 71 (3), 409-411. doi:10.1016/s0016-5085(76)80445-3

Vallance, P., Collier, J., and Moncada, S. (1989). Nitric Oxide Synthesised from L-Arginine Mediates Endothelium Dependent Dilatation in Human Veins In Vivo. Cardiovasc. Res. 23 (12), 1053-1057. doi:10.1093/cvr/23.12.1053

Van den Houte, K., Scarpellini, E., Verbeure, W., Mori, H., Schol, J., Masuy, I., et al. (2020). The Role of GI Peptides in Functional Dyspepsia and Gastroparesis: A Systematic Review. Front. Psychiatry 11, 172. doi:10.3389/fpsyt.2020.00172

Vialou, V., Bagot, R. C., Cahill, M. E., Ferguson, D., Robison, A. J., Dietz, D. M., et al. (2014). Prefrontal Cortical Circuit for Depression- and Anxiety-Related Behaviors Mediated by Cholecystokinin: Role of FosB. J. Neurosci. 34 (11), 3878-3887. doi:10.1523/jneurosci.1787-13.2014

Villar, H. V., Fender, H. R., Rayford, P. L., Bloom, S. R., Ramus, N. I., and Thompson, J. C. (1976). Suppression of Gastrin Release and Gastric Secretion by Gastric Inhibitory Polypeptide (GIP) and Vasoactive Intestinal Polypeptide (VIP). Ann. Surg. 184 (1), 97-102. doi:10.1097/00000658-197607000-00016

Virdis, A., Lerman, L. O., Regoli, F., Ghiadoni, L., Lerman, A., and Taddei, S. (2016). Human Ghrelin: A Gastric Hormone with Cardiovascular Properties. Curr. Pharm. Des. 22 (1), 52-58. doi:10.2174/1381612822666151119144458

Viteri, A. L., Poppell, J. W., Lasater, J. M., and Dyck, W. P. (1975). Renal Response to Secretin. J. Appl. Physiol. 38 (4), 661-664. doi:10.1152/jappl.1975.38.4.661

Volante, M., Allìa, E., Gugliotta, P., Funaro, A., Broglio, F., Deghenghi, R., et al. (2002). Expression of Ghrelin and of the GH Secretagogue Receptor by Pancreatic Islet Cells and Related Endocrine Tumors. J. Clin. Endocrinol. Metab. 87 (3), 1300-1308. doi:10.1210/jcem.87.3.8279

Walder, C. E., Thiemermann, C., and Vane, J. R. (1990). Endothelium-derived Relaxing Factor Participates in the Increased Blood Flow in Response to Pentagastrin in the Rat Stomach Mucosa. Proc. Biol. Sci. 241 (1302), 195-200. doi:10.1098/rspb.1990.0085

Wallace, J. L. (2012). Hydrogen Sulfide: a rescue Molecule for Mucosal Defence and Repair. Dig. Dis. Sci. 57 (6), 1432-1434. doi:10.1007/s10620-012-2119-2

Wang, R. (2002). Two's Company, Three's a Crowd: Can H2S Be the Third Endogenous Gaseous Transmitter?. FASEB j. 16 (13), 1792-1798. doi:10.1096/ fj.02-0211hyp

Watkins, C. C., Boehning, D., Kaplin, A. I., Rao, M., Ferris, C. D., and Snyder, S. H. (2004). Carbon Monoxide Mediates Vasoactive Intestinal PolypeptideAssociated Nonadrenergic/noncholinergic Neurotransmission. Proc. Natl. Acad. Sci. 101 (8), 2631-2635. doi:10.1073/pnas.0308695100

Watson, S. A., Grabowska, A. M., El-Zaatari, M., and Takhar, A. (2006). Gastrin Active Participant or Bystander in Gastric Carcinogenesis?. Nat. Rev. Cancer 6 (12), 936-946. doi:10.1038/nrc2014

Wen, Y. D., Wang, H., and Zhu, Y. Z. (2018). The Drug Developments of Hydrogen Sulfide on Cardiovascular Disease. Oxid Med. Cel Longev 2018, 4010395. doi:10.1155/2018/4010395

West, S. D., Helmer, K. S., Chang, L. K., Cui, Y., Greeley, G. H., and Mercer, D. W. (2003). Cholecystokinin Secretagogue-Induced Gastroprotection: Role of Nitric Oxide and Blood Flow. Am. J. Physiology-Gastrointestinal Liver Physiol. 284 (3), G399-G410. doi:10.1152/ajpgi.00130.2002

Wierup, N., Bjorkqvist, M., Westrom, B., Pierzynowski, S., Sundler, F., and Sjolund, K. (2007). Ghrelin and Motilin Are Cosecreted from a Prominent Endocrine Cell Population in the Small Intestine. J. Clin. Endocrinol. Metab. 92 (9), 3573-3581. doi:10.1210/jc.2006-2756

Wiley, K. E., and Davenport, A. P. (2002). Comparison of Vasodilators in Human Internal Mammary Artery: Ghrelin Is a Potent Physiological Antagonist of Endothelin-1. Br. J. Pharmacol. 136 (8), 1146-1152. doi:10.1038/sj.bjp.0704815
Wu, L., and Wang, R. (2005). Carbon Monoxide: Endogenous Production, Physiological Functions, and Pharmacological Applications. Pharmacol. Rev. 57 (4), 585-630. doi:10.1124/pr.57.4.3

Xiao, Q., Boushey, R. P., Drucker, D. J., and Brubaker, P. L. (1999). Secretion of the Intestinotropic Hormone Glucagon-like Peptide 2 Is Differentially Regulated by Nutrients in Humans. Gastroenterology 117 (1), 99-105. doi:10.1016/s00165085(99)70555-x

Xu, X., Sook Jhun, B., Hoon Ha, C., and Jin, Z. G. (2008). Molecular Mechanisms of Ghrelin-Mediated Endothelial Nitric Oxide Synthase Activation. Endocrinology 149 (8), 4183-4192. doi:10.1210/en.2008-0255

Yamada, K., Emson, P., and Hokfelt, T. (1996). Immunohistochemical Mapping of Nitric Oxide Synthase in the Rat Hypothalamus and Colocalization with Neuropeptides. J. Chem. Neuroanat. 10 (3-4), 295-316. doi:10.1016/08910618(96)00133-0

Yamagata, T., Urano, H., Weeber, E. J., Nelson, D. L., and Nishijima, I. (2008). Impaired Hippocampal Synaptic Function in Secretin Deficient Mice. Neuroscience 154 (4), 1417-1422. doi:10.1016/j.neuroscience.2008.04.037

Yang, B., Goulet, M., Boismenu, R., and Ferguson, A. V. (2004). Secretin Depolarizes Nucleus Tractus Solitarius Neurons through Activation of a Nonselective Cationic Conductance. Am. J. Physiology-Regulatory, Integr. Comp. Physiol. 286 (5), R927-R934. doi:10.1152/ajpregu.00600.2003

Yang, J., Minkler, P., Grove, D., Wang, R., Willard, B., Dweik, R., et al. (2019). Nonenzymatic Hydrogen Sulfide Production from Cysteine in Blood Is Catalyzed by Iron and Vitamin B6. Commun. Biol. 2, 194. doi:10.1038/s42003-019-0431-5

You, X. J., Xu, C., Lu, J. Q., Zhu, X. Y., Gao, L., Cui, X. R., et al. (2011). Expression of Cystathionine Beta-Synthase and Cystathionine Gamma-Lyase in Human Pregnant Myometrium and Their Roles in the Control of Uterine Contractility. PLoS One 6 (8), e23788. doi:10.1371/journal.pone.0023788

Zerbib, F., Bruley Des Varannes, S., Scarpignato, C., Leray, V., D’Amato, M., Rozé, C., et al. (1998). Endogenous Cholecystokinin in Postprandial Lower Esophageal Sphincter Function and Fundic Tone in Humans. Am. J. Physiology-Gastrointestinal Liver Physiol. 275 (6), G1266-G1273. doi:10.1152/ajpgi.1998.275.6.g1266

Zhao, D., Meyer-Gerspach, A. C., Deloose, E., Iven, J., Weltens, N., Depoortere, I., et al. (2018). The Motilin Agonist Erythromycin Increases Hunger by Modulating Homeostatic and Hedonic Brain Circuits in Healthy Women: a Randomized, Placebo-Controlled Study. Sci. Rep. 8 (1), 1819. doi:10.1038/ s41598-018-19444-5

Zigman, J. M., Jones, J. E., Lee, C. E., Saper, C. B., and Elmquist, J. K. (2006). Expression of Ghrelin Receptor mRNA in the Rat and the Mouse Brain. J. Comp. Neurol. 494 (3), 528-548. doi:10.1002/cne.20823

Zuelli, F. M. d. G. C., Cárnio, E. C., and Saia, R. S. (2014). Cholecystokinin Protects Rats against Sepsis Induced by Staphylococcus aureus. Med. Microbiol. Immunol. 203 (3), 165-176. doi:10.1007/s00430-014-0328-3

Conflict of Interest: The authors declare that the research was conducted in the absence of any commercial or financial relationships that could be construed as a potential conflict of interest.

Copyright $\odot 2021$ Verbeure, van Goor, Mori, van Beek, Tack and van Dijk. This is an open-access article distributed under the terms of the Creative Commons Attribution License (CC BY). The use, distribution or reproduction in other forums is permitted, provided the original author(s) and the copyright owner(s) are credited and that the original publication in this journal is cited, in accordance with accepted academic practice. No use, distribution or reproduction is permitted which does not comply with these terms. 